Review

\title{
Integration of cardiovascular risk assessment with COVID-19 using artificial intelligence
}

Jasjit S. Suri ${ }^{1, *}$, Anudeep Puvvula $^{1,2} \oplus$, Misha Maihail $^{1,3}$, Mainak Biswas ${ }^{4} \oplus$, Ankush D Jamthikar ${ }^{5}$, Luca Saba ${ }^{6}$ Gavino Faa ${ }^{7}$, Inder M. Singh ${ }^{1}$, Ronald Oberleitner ${ }^{8}$, Monika Turk ${ }^{9}$, Saurabh Srivastava ${ }^{10}$, Paramiit S. Chadha ${ }^{1}$, Harman S. Suri ${ }^{11}$, Amer M. Johri ${ }^{12}$, Vijay Nambi ${ }^{13}$, J Miguel Sanches ${ }^{14} \oplus$, Narendra N. Khanna ${ }^{15}$, Klaudija Viskovic ${ }^{16} \oplus_{\text {, }}$ Sophie Mavrogeni ${ }^{17}{ }^{\oplus}$, John R. Laird ${ }^{18}$, Arindam Bit ${ }^{19}$, Gyan Pareek ${ }^{20}$, Martin Miner ${ }^{21}$, Antonella Balestrieri ${ }^{6} \mathcal{C}_{\text {, }}$

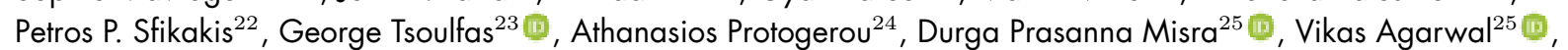
George D. Kitas ${ }^{26,27}$, , Raghu Kolluri ${ }^{28}{ }^{\oplus}$, Jagjit Teji ${ }^{29}{ }^{\oplus}$, Michele Porcu ${ }^{6}$, Mustafa Al-Maini ${ }^{30}$, Ann Agbakoba ${ }^{31}$, Meyypan Sockalingam ${ }^{32}$, Ajit Sexena ${ }^{15}$, Andrew Nicolaides ${ }^{33}$ C. Aditya Sharma $^{34}$, Vijay Rathore ${ }^{35}$, Vijay Viswanathan ${ }^{36}$, Subbaram Naidu ${ }^{37}$ and Deepak L. Bhatt ${ }^{38}$ (C)

${ }^{1}$ Stroke Monitoring and Diagnostic Division, AtheroPoint ${ }^{T M}$, Roseville, 95747, CA, USA

${ }^{2}$ Annu's Hospitals for Skin and Diabetes, Nellore, 524001, AP, India

${ }^{3}$ Oakmount High School and AtheroPoint ${ }^{T M}$, Roseville, 95747, CA, USA

${ }^{4}$ JIS University, Kolkata, 700001, West Bengal, India

${ }^{5}$ Department of ECE, Visvesvaraya National Institute of Technology, Nagpur, 440010, MH, India

${ }^{6}$ Department of Radiology, Azienda Ospedaliero Universitaria (A.O.U.), 09100, Cagliari, Italy

${ }^{7}$ Department of Pathology, AOU of Cagliari, 09100, Italy

${ }^{8}$ Behavior Imaging, Boise, 83701, ID, USA

${ }^{9}$ The Hanse-Wissenschaftskolleg Institute for Advanced Study, 27749, Delmenhorst, Germany

${ }^{10}$ School of Computing Science \& Engineering, Galgotias University, 201301, Gr. Noida, India

${ }^{11}$ Brown University, Providence, 02912, RI, USA

${ }^{12}$ Department of Medicine, Division of Cardiology, Queen's University, Kingston, BOP 1RO, Ontario, Canada

${ }^{13}$ Department of Cardiology, Baylor College of Medicine, 77001, TX, USA

${ }^{14}$ Institute of Systems and Robotics, Instituto Superior Tecnico, 1000-001, Lisboa, Portugal

${ }^{15}$ Department of Cardiology, Indraprastha APOLLO Hospitals, 110001, New Delhi, India

${ }^{16}$ University Hospital for Infectious Diseases, 10000, Zagreb, Crotia

${ }^{17}$ Cardiology Clinic, Onassis Cardiac Surgery Center, 10431 , Athens, Greece

${ }^{18}$ Heart and Vascular Institute, Adventist Health St. Helena, St Helena, 94574, CA, USA

${ }^{19}$ Department of Biomedical Engineering, NIT, Raipur, 783334, CG, India

${ }^{20}$ Minimally Invasive Urology Institute, Brown University, Providence, 02901, Rhode Island, USA

${ }^{21}$ Men's Health Center, Miriam Hospital Providence, 02901, Rhode Island, USA

${ }^{22}$ Rheumatology Unit, National Kapodistrian University of Athens, 104 31, Greece

${ }^{23}$ Aristoteleion University of Thessaloniki, 544 53, Thessaloniki, Greece

${ }^{24}$ National \& Kapodistrian University of Athens, 10431 , Greece

${ }^{25}$ Sanjay Gandhi Postgraduate Institute of Medical Sciences, Lucknow, 226001, UP, India

${ }^{26}$ Academic Affairs, Dudley Group NHS Foundation Trust, DY1, Dudley, UK

${ }^{27}$ Arthritis Research UK Epidemiology Unit, Manchester University, M13, Manchester, UK

${ }^{28}$ OhioHealth Heart and Vascular, 45874, Ohio, USA

${ }^{29}$ Ann and Robert H. Lurie Children's Hospital of Chicago, 60601, Chicago, USA

${ }^{30}$ Allergy, Clinical Immunology and Rheumatology Institute, M3H 6A7, Toronto, Canada

${ }^{31}$ University of Lagos, 100001 , Lagos, Nigeria

${ }^{32}$ MV Center of Diabetes, 600001 , Chennai, India

${ }^{33}$ Vascular Screening and Diagnostic Centre and University of Nicosia Medical School, 999058, Cyprus

${ }^{34}$ Division of Cardiovascular Medicine, University of Virginia, Charlottesville, 22901, VA, USA

${ }^{35}$ Nephrology Department, Kaiser Permanente, Sacramento, 94203, CA, USA

${ }^{36}$ MV Hospital for Diabetes and Professor M Viswanathan Diabetes Research Centre, 600001, Chennai, India

${ }^{37}$ Electrical Engineering Department, University of Minnesota, Duluth, 55801, MN, USA

${ }^{38}$ Brigham and Women's Hospital Heart \& Vascular Center, Harvard Medical School, Boston, 02108, MA, USA

*Correspondence: jasjit.suri@atheropoint.com (Jasjit S. Suri)

DOI: 10.31083 /j.rcm.2020.04.236

This is an open access article under the CC BY 4.0 license (https://creativecommons.org/licenses/by/4.0/). 
Artificial Intelligence (AI), in general, refers to the machines (or computers) that mimic "cognitive" functions that we associate with our mind, such as "learning" and "solving problem". New biomarkers derived from medical imaging are being discovered and are then fused with non-imaging biomarkers (such as office, laboratory, physiological, genetic, epidemiological, and clinical-based biomarkers) in a big data framework, to develop Al systems. These systems can support risk prediction and monitoring. This perspective narrative shows the powerful methods of Al for tracking cardiovascular risks. We conclude that Al could potentially become an integral part of the COVID-19 disease management system. Countries, large and small, should join hands with the WHO in building biobanks for scientists around the world to build Albased platforms for tracking the cardiovascular risk assessment during COVID-19 times and long-term follow-up of the survivors.

\section{Keywords}

COVID-19; cardiovascular; myocarditis; artificial intelligence; risk assessment; non-invasive monitoring

\section{Introduction}

The SARS-CoV-2 is a single-stranded ribonucleic acid (RNA) virus belongs to the corona family of viruses, which can lead to several pulmonary and extrapulmonary complications such as viral pneumonia, acute respiratory distress syndrome (ARDS), cardiovascular disease, cerebrovascular disease, or even systemic hyper-inflammation syndrome that leading to a multiorgan failure (WHO, 2020). The first case of SARS-CoV-2 is diagnosed in Wuhan, the capital city of the Hubei province in the People's Republic of China (Eder, 2020; Edmonds, 2020). It was suspected that the SARS-CoV-2 was by horseshoe bats, mutating into pangolin as intermittent hosts, and then made their way into humans (Bale, 2020). The SARS-CoV-2 is believed to be transmitted from human-to-human mainly through virus-laden droplets (generated by coughing, sneezing, or talking), and through close contacts with infected persons or through touching surfaces or objects with the virus on it (Tan and Aboulhosn, 2020). It has a spread function of three $\left(\mathrm{R}_{o}=3\right)$, which means every person, on average, can infect another three people, thereby growing exponentially. It can severely affect or be fatal to high-risk category groups such as the elderly (age $>60$ years), or patients having pre-existing conditions like chronic obstructive pulmonary disease, diabetes, asthma, hypertension, cardiovascular diseases, obesity, and cancer. Due to the combination of its high contiguousness and virulence, it has become a global threat causing the pandemic ( $\mathrm{N}$. Chen et al., 2020b; Guan et al., 2020; C. Huang et al., 2020; Wang and Bhatt, 2020; Wu and McGoogan, 2020). As of $\mathbf{2 5}^{\text {th }}$ October 2020, COVID-19 has nearly $\mathbf{4 3}$ million infections and nearly 1.1 million deaths worldwide (Worldometer, 2020). It is speculated that the spread of COVID-19 is due to international travels from Asia to Europe and the USA (Eder, 2020; Edmonds, 2020). The top ten countries with the most cases of COVID-19 are the United States of America, India, Brazil, Russia, Spain, France, Argentina, Colombia, Mexico, Peru, and the United Kingdom (see Fig. 1, left). They account for $\mathbf{8 0 \%}$ of all mortality, of which $\mathbf{2 1 \%}$ are in the United States alone, consisting of $\mathbf{2 1 0 , 0 0 0}$ deaths (Jeffrey, 2020; Worldometer, 2020). Interesting recent studies shown the data of cardiovascular entity is more often and serious complication which increases mortality and morbidity in COVID-19 patients (Kwenandar et al., 2020; Wu and McGoogan, 2020). Thus, it is a wake-up call to understand the nature of COVID-19, how it causes organ failure, especially heart, and how we can monitor these patients before, during, or long-term follow-up of the survivors after COVID-19 times using smart, accurate, and affordable systems.

The pathophysiology of the SARS-CoV-2 is not yet fully established. Recent studies have shown that the virus gains entry into the cells through the angiotensin-converting enzyme 2 (ACE2) receptors that clamp the S-protein on the surface of SARS-CoV-2 (see Fig. 1, right) (Hoffmann et al., 2020). The ACE 2 receptors are human homologs that are widely expressed in the cells of the heart, lungs, kidney, and intestine (Turner et al., 2004). The ACE2 plays a counterbalancing role in the renin angiotensin-converting system (RAS) (Akhmerov and Marbán, 2020; Zou et al., 2020) and is a carboxypeptidase that converts angiotensin II (Ang II) into angiotensin (1-7) (Ang 1-7) (Donoghue et al., 2000).

Reports from admitted patients in various hospitals in Wuhan suggest serious cardiac injury in at least $12 \%-26 \%$ of admitted patients (L. Chen et al., 2020; C. Huang et al., 2020; S. Shi et al., 2020; Zheng et al., 2020). The cardiac injury is thought to be due to the presence of mural cells (pericytes) in the heart, having a high expression of ACE2 (L. Chen et al., 2020). The recent article by Libby (2020) also showed that the release of cytokines during the infection could affect the intramural coronary vessels of the patients without any pre-existing cardiovascular disease (CVD). It has been seen that patients who had SARS showed tissue fibrosis and microangiopathy, and thus needed their heart to be monitored (Ferreira et al., 2018; Inciardi et al., 2020b; Wu and McGoogan, 2020). Wu et al. (2017) had recently emphasized the role of studying the long-term effects of clinical treatments in SARS patients. The authors compared SARS survivors against healthy controls and showed that there were significant differences in the serum metabolomes and thus there is a need for special monitoring of patients with SARS. The patients with cardiovascular disorders have a high vulnerability to SARS-CoV-2 (S. Shi et al., 2020) that can lead to complications such as myocardial injury, systemic inflammation, which further leads to cardiac failure, plaque rupture, arrhythmias, venous thromboembolism, and coronary thrombosis (Bansal, 2020; Driggin et al., 2020). The SARSCoV-2 may predispose patients to thrombotic disease due to excessive inflammation, platelet activation, endothelial dysfunction, and stasis (Bikdeli et al., 2020). Therefore, it is of prime importance to address the issues like, how do we monitor patients (a) who are asymptomatic or mildly symptomatic, (b) have moderate to severe symptoms of COVID-19 perhaps requiring hospitalization, (c) have recovered from COVID-19 in an early pandemic, (d) who can get re-infected after recovery, and (e) what happens to the patients who have the acute CVD due to hospital overloading (Huet et al., 2020). Should we have a risk assessment system in place, which can study and regularly monitor cardiac conditions? The complete management requires more than just temporary checkups of patients, but a global tracking scheme that can prepare us for 

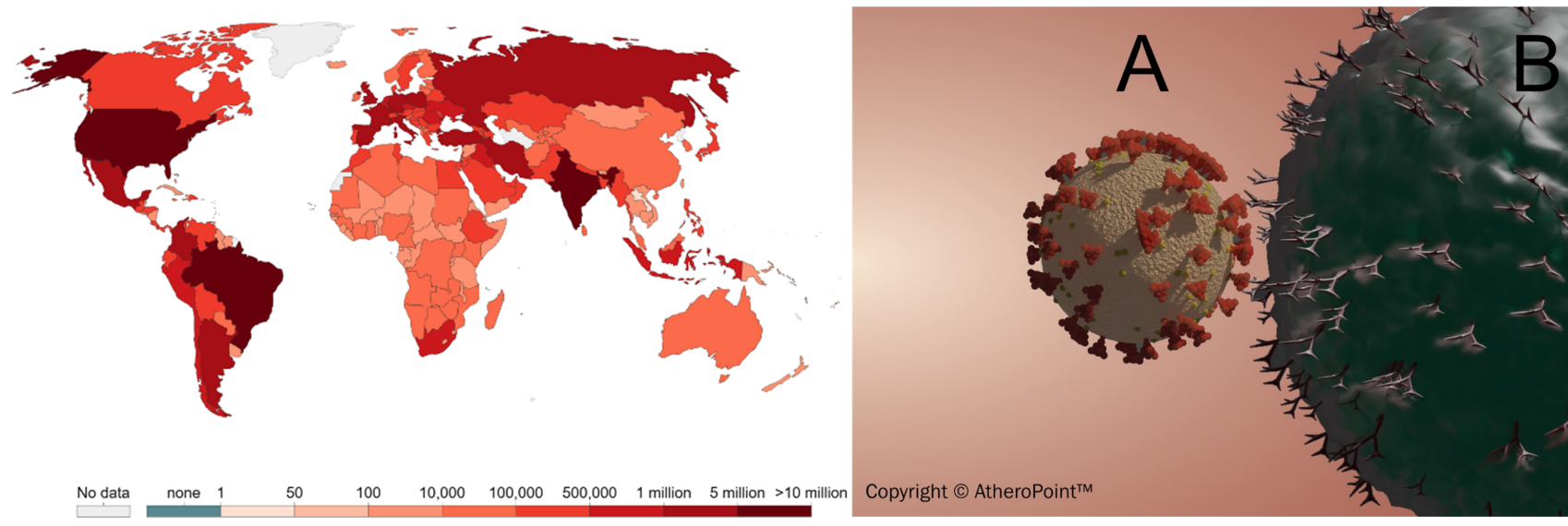

Fig. 1. Left: World map showing the COVID-19 (Courtesy: https: / / ourworldindata.org). Right: SARS-binding to ACE2 receptor by the spike protein (S protein) to gain intracellular entry (Courtesy AtheroPoint ${ }^{\mathrm{TM}}$, Roseville, CA, USA).

further pandemics. It is thus essential to understand the pathways for heart injury, and further to understand what kinds of tools and techniques one can use to track pandemics like COVID-19, thereby preventing its spread. This can further help in the development of the drug-delivery systems.

Artificial Intelligence (AI) (Flach, 2001; James et al., 2013) techniques such as machine learning (ML) and deep learning (DL) in medicine refers to the cognitive functions by machines in understanding trends, generating warnings, diagnosis, prognosis, and treatment of patients (Naudé, 2020). It is already deeply embedded in several fields of medicine, such as medical imaging (Biswas et al., 2019; Saba et al., 2019), drug-delivery design (Hassanzadeh et al., 2019), and computational biology (Angermueller et al., 2016; Libbrecht and Noble, 2015). The advancements in Internetof-Things (IoT) technologies have made a significant effort towards "call-to-action for telemedicine" (Ohannessian et al., 2020; Thomas et al., 2020) that would strengthen tele-consultation, remote patient monitoring, and disease management protocols (Portnoy et al., 2020; Wang and Bhatt, 2020), and computer-aided diagnosis in general (Acharya et al., 2008; El-Baz and Suri, 2011). Evidence suggests that telemedicine (TM) (Ganasegeran and Abdulrahman, 2020), in combination with AI has the potential to locate, diagnose, and treat the patients in times of epidemics such as the Zika pandemic in 2007-17 (Daughton and Paul, 2019) and Influenza A H1N1 Pandemic in 2009-11 (Signorini et al., 2011). Thus, the AI-based telemedicine technologies have the potential to provide ideal solutions in non-invasive patient care systems, which is suitable for the current and long-term tracking of COVID-19 patients. This perspective is mainly geared towards the tools and techniques for COVID-19 patient management using AI-based solutions in a big data framework for pandemic management and provides recommendations for future pandemic prevention.

This paper is illustrated in 7 sections, which are as follows. Section 1 covers introduction (already explained above) and Section 2 covers the basics of four pathways leading to cardiac injury. The motivation and role of AI for risk assessment of CVD is presented in Section 3. Section 4 shows the applications of imaging and non-imaging-based applications of $\mathrm{AI}$ in medicine. Section 5 presents the tracking of surrogate markers for CVD during COVID times and beyond. Section 6 presents the recommendations and preparedness for handling current and future pandemics. The conclusion of this review is presented in Section 7.

\section{Pathophysiology and the pathways to heart injury \\ 2.1 Importance of ACE2 receptor}

Several studies have found that SARS-CoV-2 uses the ACE2 receptor for entering into the cell (de Wit et al., 2016; Hoffmann et al., 2020; Wu et al., 2012) (see Fig. 1), right where the SARSCoV-2 is labeled as A and the ACE2 as well as the gray color cell, labeled B). ACE2 is a carboxypeptidase that converts angiotensin II (Ang II) into angiotensin (1-7) (Ang 1-7) and is homologous to angiotensin-converting enzyme 1 (ACE1). ACE2 is key enzyme in the renin angiotensin-converting system (RAS) (Bernstein, 2002; Donoghue et al., 2000; Turner et al., 2004). ACE1 and ACE2 are widely expressed in cardiomyocytes, cardiac fibroblasts, coronary endothelial, mural cells (in the heart), type 2 pneumocytes (in the lungs), and enterocytes (in the intestine) (Williams and Scholey, 2018; Zou et al., 2020).

\subsection{Pathophysiology of SARS-CoV-2 on the myocardial cell}

Several published studies have shown that SARS-CoV-2 can cause both pulmonary and extrapulmonary complications like cardiovascular (CV) complications (Geng et al., 2020; Xiong et al., 2020). Another solid evidence by Zunyou, Wu et al. (Wu and McGoogan, 2020), and Kevin J et al. (Clerkin et al., 2020) submitted a summary of the report to the Chinese center for disease control and prevention indicating 1023 deaths in 44672 confirmed cases with COVID-19, i.e. a case-fatality rate (CFR) of 2.3 , and stating that patients with underlying cardiovascular disease or hypertension had a higher CFR compared with people without comorbidities. Thus, it is a wake-up call to understand the nature of COVID-19, how it causes organ failure, especially heart and how we can monitor these patients before, during, or long-term follow-up of the survivors after COVID-19 times using smart, accurate, and affordable systems. Additionally another interesting Chinese cohort study by Shi et al. (S. Shi et al., 2020) found that COVID patients with cardiac injury had high mortality compared with those without cardiac abnormality $51.2 \%$ vs $4.5 \%$ in 416 hospitalized patients between January 2020-February 2020. The fol- 
lowing are the common mechanisms responsible for CV complications in COVID-19, these include (i) myocardial oxygen demand mismatch, (ii) dysregulation of the RAAS after SARS-CoV-2, (iii) systemic inflammatory response, and (iv) myocarditis.

Pathway (I) Myocardial oxygen demand mismatch (shown in Fig. 2): This pathway triggers by entering of SARS-CoV-2 through the respiratory pathway and binds to the ACE2 receptor on the surface of alveolar type 2 (AT2) cells in the pulmonary epithelium (Filardi and Morano, 2020; Zheng et al., 2020). These results in exaggerated neutrophil accumulation cause enhance in vascular permeability of subendothelial space which leads to the formation of alveolar exudates (C. Huang et al., 2020; Wang et al., 2019). Further, it leads to pulmonary edema resulting in an alveolar gas exchange disorder known as "acute respiratory distress syndrome" (ARDS), which results in depletion of oxygen levels causing hypoxia (Barnes et al., 2020; Fadini et al., 2020). Supporting evidence by Kwenandar et al. (2020) has shown that COVID-19 patients had up to $33 \%$ prevalence of cardiovascular manifestations like myocardial injury (MI), sudden cardiac arrest, heart failure, and coagulation abnormality. Additionally, S. Shi et al. (2020) has shown that SARS-CoV can infect pulmonary and myocardial cells through the ACE2 pathway, thereby causing lung edema, ARDS, and myocardial injury.

Pathway (II) Dysregulation of the RAAS after SARS-CoV-2 (shown in Fig. 2): This pathway gets initiated due to intracellular host cell entry of SARS-CoV-2. Resulting in the loss of ACE2, which in turn leads to (a) a decrease in levels of cardioprotective Ang (1-7) (shown in a panel of green color) and (b) an increase in levels of Ang II (shown in a panel of pink color). Hence, the increase of Ang II promotes endothelial dysfunction and inflammations, accelerating the process of atherosclerosis (Dong et al., 2008; Lovren et al., 2008; Sahara et al., 2014; Tikoo et al., 2015; Yousif et al., 2012; Zhang et al., 2010). SARS-CoV-2 entry causes the downregulation of ACE2 levels and the activation of RAAS (Oudit et al., 2009). Generally, in RAAS, Ang-I is converted to Ang-II by ACE1. Ang-II is associated with several processes and is thought to promote vasoconstriction, proinflammation, profibrotic, prothrombosis, and proliferation of cells that are harmful to the human body. Hence Ang (1-7) is generated from degradation of Ang II by ACE2 as a counter-regulatory mechanism (Zhang and Baker, 2018), causing the opposite effects of Ang II. Ang (17), therefore, results in vasodilatation, antiapoptotic, antifibrotic, antithrombotic, and antiproliferative effects that are cardioprotective. During SARS-CoV-2 infection, reduction in ACE2 results in the (a) down-regulation of processes associated with Ang (1-7) and (b) activation of all the processes related to Ang II, has a detrimental effect on the blood vessels, thereby leading to endothelial cell damage, which leads to atherosclerotic cardiovascular events.

Pathway (III-A) Systemic inflammatory response (shown in Fig. 2): An increase in Ang II promotes inflammatory cytokines that exaggerate an inflammatory response causing a cytokine storm. It represents an advanced stage of severe illness characterized by multiple organ failure (Siddiqi and Mehra, 2020). The rise in these inflammatory cytokines includes interleukin (IL)-6, IL-7, IL-22, CXCL-10, which results in a decrease in plaque stability that favors the plaque rupture causes micro thrombosis and cardiac injury (Y. Huang et al., 2020; Schoenhagen et al., 2002;
Xiong et al., 2020). As supporting evidence by Ruan et al. (2020) presented a study with 150 COVID-19 patients from Wuhan that higher levels of inflammatory cytokines patients have high mortality. Additionally, Guo et al. (2020) have shown that COVID-19 patients had elevated inflammatory cytokines and troponin (TnT) suggestive of cardiac injury and an increase in mortality.

Pathway (III-B) Myocarditis and SARS-CoV-2 (shown in Fig. 2): Myocarditis is an inflammatory response of cardiac myocytes which may be results due to SARS-CoV-2 infection (Siripanthong et al., 2020), The association between myocarditis and coronavirus is well-known from the times of Middle East respiratory syndrome coronavirus (MERS-CoV) infection, but still the evident link between SARS-CoV-2 and myocarditis is not yet well established. We hypothesized that viral infection can reaches heart via intravascular circulation and activates immune response, aimed to clearing the virus. These causes in increasing of cytokines and immune cell infiltration in the myocardium (Blauwet and Cooper, 2010). As a consequence these results in direct virus related cardiac injury (virus directly infects and damages cadiac cells) due to autoimmunity (through the mechanisim of molecular mimicry the activated immune system also attacks the cardiac cells). Further it was noticed that the patients with history of myocarditis does not subsides but persist long time which can lead to dilated cardiomyopathy (Blauwet and Cooper, 2010) and increases the risk of mortality (Alhogbani, 2016; Hinojar et al., 2016).

\section{The role of machine learning in CVD risk assessment of COVID-19 heart patients 3.1 Blood vessel damage due to COVID-19 causing heart injury}

Acute cardiac injury is a commonly observed phenomenon among COVID-19 patients. In such patients, viral involvement of cardiomyocytes and systemic inflammation are common mechanisms for cardiac injury Bansal (2020). The understanding of interrelationship of COVID-19 and CVD is important for optimal management of such patients Bansal (2020). Recently, both Lin et al. (2012) and Gasso et al. (2020) in their independents work, showed a case study where the patient with multivessel spontaneous coronary artery dissection (SCAD) having SARS-CoV-2 led to myocardial infarction. Tan et al. (Tan and Aboulhosn, 2020) concluded that COVID-19 causes severe injury to the pulmonary and cardiovascular system, even leading to death. The authors shared that patients having congenital heart disease (CHD) are suspect to COVID-19, leading to comorbidities. Lippi et al. (2020) showed that the 14 days quarantine period requires physical activities for the prevention of metabolic and cardiovascular loss; otherwise, it will lead to impairing aerobic capability and increasing hypertension. The authors categorized this period as a preventive cardiological framework. South et al. (2020) was the first one to question the potential consequence of the renin-angiotensinaldosterone system (RAAS) blockade to COVID-19 patients having respiratory disease, thereby posing a question about the blockage of ACE2 and its viability to attenuate the COVID-19. Further, this study suggested the role of monitoring COVID-19 patients over time based on the COVID-19 severity. Fang et al. (2020) investigated the role of diabetes mellitus and hypertension in the augmented risk of COVID-19. The authors reported that ACE2 receptors are found in epithelial cells of the lung, blood vessels, 

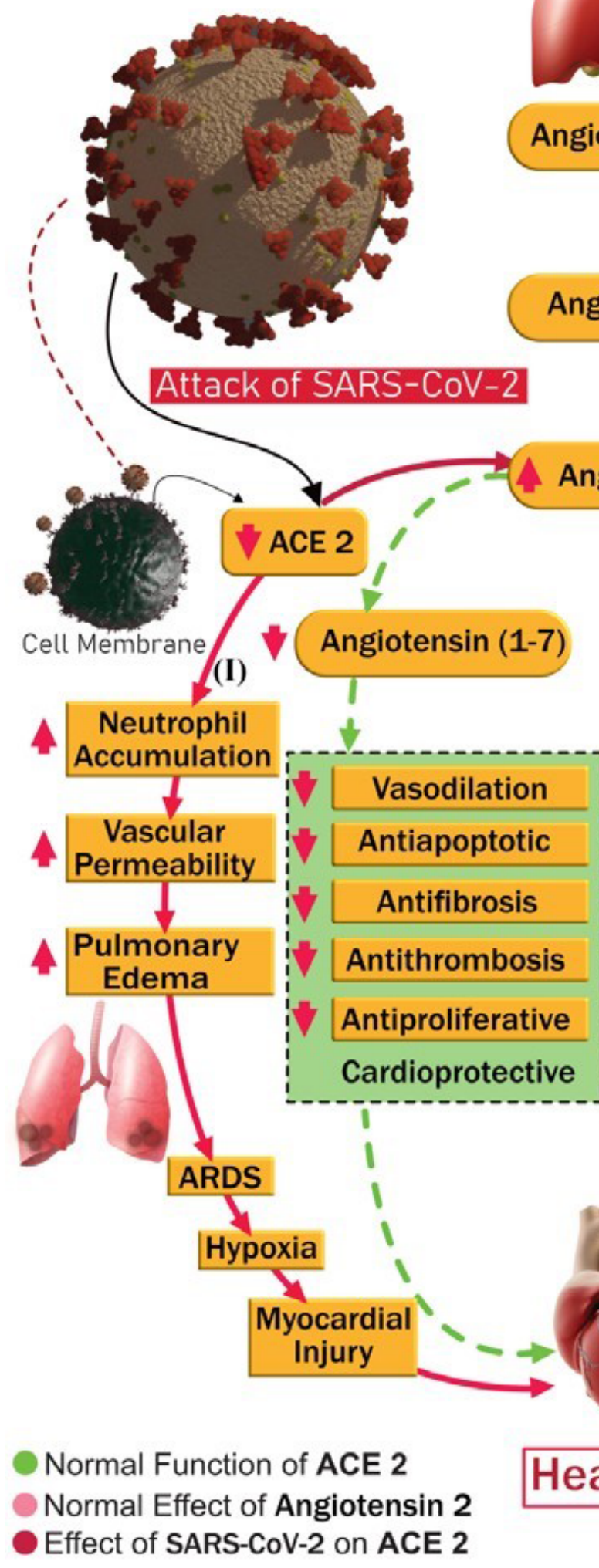

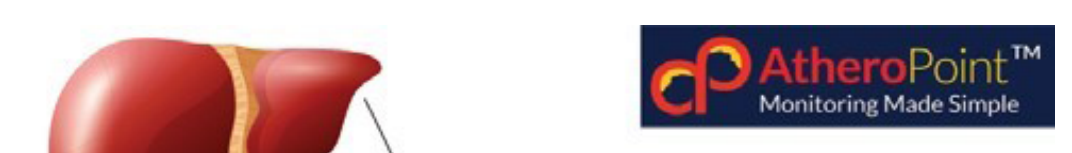

Angiotensinogen
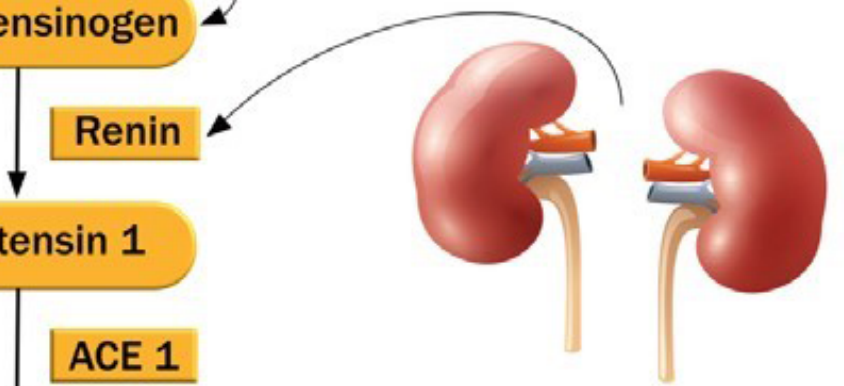

ACE 1

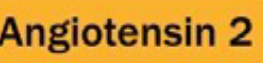

(II)

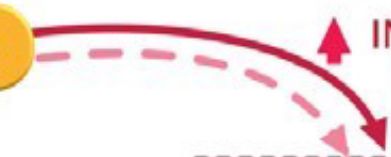

NCREASED

LEVELS

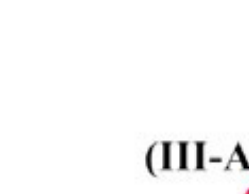


al., 2020; Viswanathan et al., 2020d), it is, therefore, vital to monitor these blood vessels of patients who got infected by COVID-19. Due to the ACE2 polymorphism, it is even essential to monitor the organ systems of COVID-19 patients. Cai (2020) showed that the smokers have ACE2 gene expression higher than the non-smokers. Since the CVD is highly related to smoking (Hejjaji et al., 2020) and smoking also severely affects the current atherosclerotic disease and increases the 10-year CVD risk (Kelishadi et al., 2004), patients who have predisposed diseases with smoking conditions are highly vulnerable to COVID-19. This requirement needs special monitoring of the blood vessels in these patients.

\subsection{Evidence of machine learning in CVD risk assessment}

AI has played a vital role in disease classification and risk stratification. Two categories of AI technologies, i.e., ML and DL have long been active in CVD risk management (Díaz, 2020). The ML (Bishop, 2006; Díaz, 2020) refers to the broad class of probabilistic, distance, and rule-based models used in the characterization of diseases and risk stratification, whereas, the DL (Krizhevsky et al., 2012; LeCun et al., 2015) refers to multiple layers of brainmimicking neural networks employed for the same. ML-based solutions have been adapted for risk stratification in different applications such as stroke (Acharya et al., 2013b; Cuadrado-Godia et al., 2018a; Jamthikar et al., 2020b,a; Martis et al., 2013). Recently, Dong et al. (2020) reviewed several image-based characteristics and the AI-based models for accurate diagnosis and better treatment and management of COVID-19 patients. The authors reviewed the imaging characteristics from computed tomography (CT), positron emission tomography (PET), chest ultrasound, and MRI. The AI-based models were used for image analysis of COVID-19 patients and reported a median AUC of 0.89 ( 0.78 to 0.98 ) and a median accuracy of $95 \%$ ( $88 \%$ to $95 \%)$. Jamthikar et al. (2020b, 2019, 2020d,a) recently showed the role of ML for CVD/stroke risk assessment by combining image-based phenotypes and standard risk factors in a big data framework. The same team developed recently methods using ML-based risk stratification for binary class (Jamthikar et al., 2020e) or multiclass frameworks (Jamthikar et al., 2020f), demonstrating superior ML-based systems (XGBoost, RF, and SVM) compared to conventional models such as Systematic Coronary Risk Evaluation score (SCORE), Framingham risk score (FRS), and Atherosclerotic CVD (ASCVD).

In a special report, the authors discussed the need of a system of preventive cardiovascular framework for coronary artery disease $(\mathrm{CAD})$ management in the $\mathrm{AI}$ and big data framework (Jamthikar et al., 2020b). Similarly, an AI-based algorithm has also been used for CVD risk assessment in several other areas (Boi et al., 2018; Jamthikar et al., 2020g; Khanna et al., 2019a). The beauty of AI methods is that the memory parameters of ML model can be trained and such trained models can be used for prediction of disease severity in patients who are asymptomatic. Within a short period, several ML-based techniques used the power of AI in COVID-19 management (Alimadadi et al., 2020; Vaishya et al., 2020). More about the role of AI in imaging/non-imaging framework will be covered in the next section.

\section{Imaging/non-imaging-based AI and its manifestations}

AI has dominated both in imaging and non-imaging fields of medicine with over 10,000 publications in the last few years. Since DL was predominantly image-based, to begin with (Krizhevsky et al., 2012; LeCun et al., 2015), it has now vigorously penetrated the imaging field (Acharya et al., 2008, 2013b; El-Baz and Suri, 2011; Liu et al., 2005; Sanches et al., 2012). On the contrary, ML has been active before DL in imaging and non-imaging paradigms. Few recent reviews have been published in the area of AI applications in cardiology (Jiang et al., 2017; Xu et al., 2020) and radiology (Biswas et al., 2019; Saba et al., 2019). We have presented and summarized a few key landmark studies.

\subsection{AI-based segmentation}

Medical images of internal organs are generally captured using CT, MRI and ultrasound modalities. DL and ML strategies have been applied to these modalities to segment the organs of interest (Suri, 2000; Suri et al., 2002). Recently a review was presented on the role of AI for data retrieval, segmentation of medical organs, and diagnosis for COVID-19 (Boi et al., 2018; F. Shi et al., 2020a). AI has also penetrated the field of cardiology for the segmentation of the heart (Avendi et al., 2016; Genovese et al., 2019) or tracking the heart over time (Carneiro and Nascimento, 2013). A shape model estimation of the entire heart using AI (Wang and Smedby, 2018) has been done. One such $3 \mathrm{D}$ model of heart that can be developed is shown in (Fig. 3). A recent book by El-Baz and Suri talks about several techniques on AI applications to cardiovascular imaging (El-Baz, 2018). This is a powerful solution to understand the severity of heart injury during and after pandemics.

\subsection{AI-based tissue characterization and classification}

Characterization of the diseased tissue against normal or risk stratification of the disease severity is well embraced by AI-based models, for example, ML-based strategies were adapted for benign vs. malignant prostate cancer (McClure et al., 2014; Pareek et al., 2013), ovarian cancer (Acharya et al., 2015, 2013c), liver cancer (Biswas et al., 2018; Kuppili et al., 2017), brain cancer (Tandel et al., 2020), plaque tissue for risk stratification, coronary artery risk stratification (Acharya et al., 2013a; Khanna et al., 2019a; Saba et al., 2017; Skandha et al., 2020) are some to say.

Also, closely knitted areas to CVD are genetics and microscopy. Genetics can be used to tackle the COVID-19 pandemic by tracking its origin (Cui et al., 2019; Jiang et al., 2020; Li et al., 2020a; Phan, 2020; J. Zhang et al., 2020a), finding reasons for the outbreak (Zhao and Yuan, 2020), and developing new vaccines (Álvarez-Machancoses et al., 2020; Hampel et al., 2020; Li et al., 2020c; Peng et al., 2020; Yan et al., 2020b; Yassine and Shah, 2020). Similarly, microscopy imaging is a very important part of AI-based COVID research for live-cell visualization to understand the behavior of SARS-CoV-2 (Lugagne et al., 2020; van Valen et al., 2016).

Patients with cancer, especially lung cancer, show an elevated risk of COVID-19 infection (L. Zhang et al., 2020b). Such patients need vigorous screening to first detect cancer using the imaging modality and segment such tumors. AI plays a vital role in tumor segmentation (Alakwaa et al., 2017; Jiang et al., 2018; Kamnitsas et al., 2017; Pereira et al., 2016; Prastawa et al., 2004; Skourt et al., 2018) and the classification of cancers (Tandel et al., 2019; Zlo- 

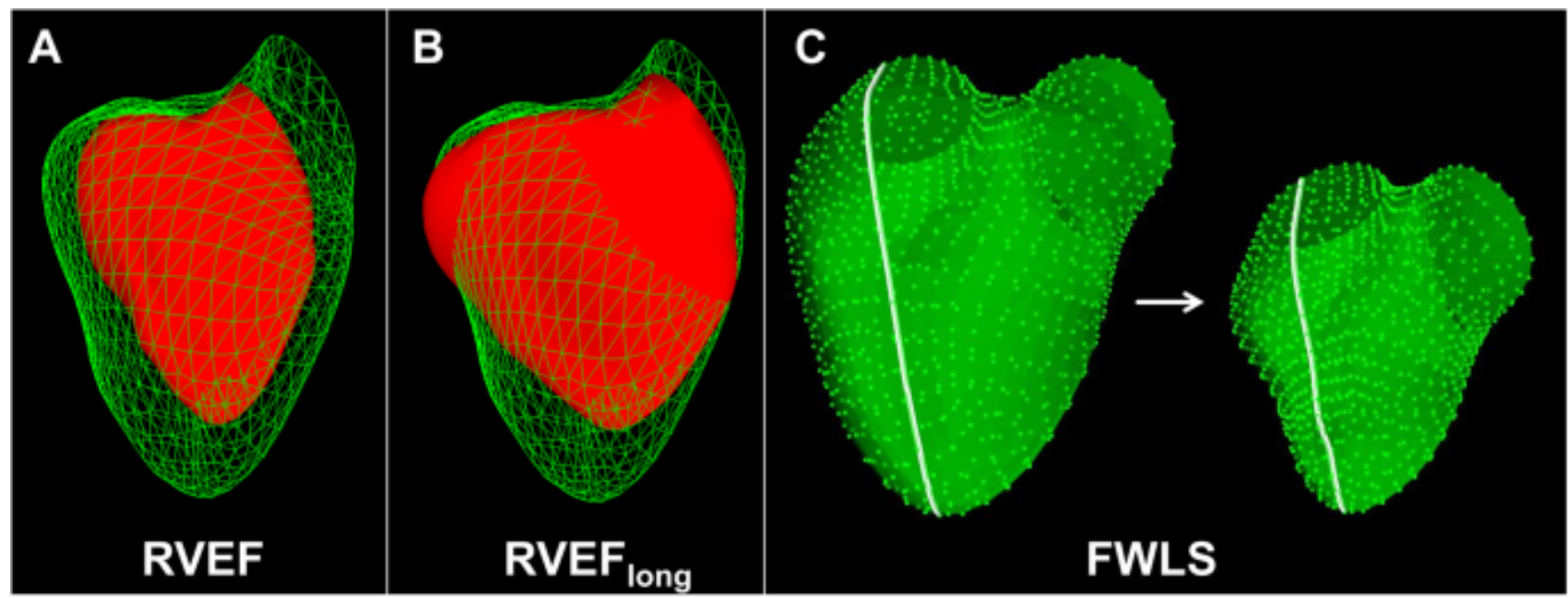

Fig. 3. 3D shape estimation of the heart (Courtesy (Keller et al., 2020)).

chower et al., 2020). Accurate detection of cancers can help in deciding the treatment plans and can further be useful in the management of COVID-19 infection.

\subsection{AI-based myocarditis imaging}

There are strong evidences suggesting microbial infection due to COVID-19 leads to myocarditis resulting in cardiac injury and inflammation (Cau et al., 2020; Siripanthong et al., 2020; Tavazzi et al., 2020; Woudstra et al., 2018). The abnormalities of heart shape can be easily visualized through different imaging modalities (Biswas et al., 2019; Suri, 2000). Nicol et al. (2020) showed the role of cardiac MRI with T2-weighted mapping sequences in identification of focal lateral subepicardial late gadolinium enhancement and myocardial inflammation. Another study by Zhao et al. (Zhao and Yuan, 2020) also showed the role of CMRI for computing the left ventricle (LV) function using 4-D imaging on myocarditis patients. In relation to myocarditis imaging in the COVID-19 era, there are many cases of AI-usage. A case controlled research was performed on 21 patients for early gadolinium enhancement (EGE) study. The patients were divided into positive and negative EGE groups to study LV parameters which were accurately detected through the AI (Yuan et al., 2019). Four examples of MR images studied for a patient admitted to Cagliari Hospital are shown in (Fig. 4). Attia et al. (2020) showed the role of AI-based ECG where the authors computed the probability of ejection fraction $(\mathrm{EF}) \leq 40 \%$ of $90.2 \%$, and echocardiographic $\mathrm{EF}$ of $35 \%$. Another patient had a pre-existing EF $\leq 40 \%$, accurately detected by AI before and after diagnosis. One other patient had a low EF detected by AI.

The extent of myocarditis damage to the heart can also be measured through echocardiographic quantification of the left ventricular ejection fraction in automated way through AI. There are several AI models for detecting these abnormalities automatically (Biswas et al., 2019). This is possible through automated border delineation of endocardial boundaries and then computation of the end-systolic and diastolic volumes. In this regard, DL has been used in several studies with varying degree of success. Hubel and Wiesel (1962) performed LV segmentation using DL with performance parameters Jaccard distance (JD) at 0.83 , average error
$(\mathrm{AV})$ at 0.91 , mean absolute distance (MAD) at 0.95 and average perpendicular error (AVP) at 0.83. An ML-based method for estimation of LV ejection fraction was developed with sensitivity and specificity at 0.90 and 0.92 , respectively for detection of EF (Asch et al., 2019). Further, any variation of normal behavior can also be detected using the AI modules. With regards to this, in one study (Ghorbani et al., 2020) a DL network was able to accurately identified the pacemaker, enlarged left atrium, left ventricular hypertrophy with an of AUC of 0.89, 0.86 and 0.75 , respectively. The performance of detection of left ventricular end systolic and diastolic volumes $\left(\mathrm{R}^{2}=0.74\right.$ and $\left.\mathrm{R}^{2}=0.70\right)$, and ejection fraction $\left(\mathrm{R}^{2}\right.$ $=0.50$ ) from a large dataset of 2850 patients.

\section{Cardiovascular risk monitoring using surrogate markers}

Since the risk of CVD is best predicted by taking the atherosclerotic burden via an imaging modality, it is preferred to use non-invasive scanning and risk assessments. This can be applied to all categories of patients, such as asymptomatic, mildly symptomatic, or severely symptomatic for COVID-19. Since the genetic makeup of the carotid artery is the same as the coronary artery (Sugiyama et al., 2001), one can choose surrogate biomarkers for risk assessment. It has been well established that one can also measure the 10-year CVD by fusing the laboratory-based blood biomarkers (LBBM) with image-based phenotypes. Thus, a five or 10-year CVD risk can also be determined while the patient with cardiac injury has a laboratory test and noninvasive carotid ultrasound scans (Johri et al., 2013; Khanna et al., 2019b; Saba et al., 2012b).

\subsection{Non-invasive monitoring of surrogate CVD markers}

We have to look for ways and means for CVD risk assessment, which is safe, reliable, and cost-effective for patients during the COVID-19 pandemic. AtheroEdge ${ }^{\mathrm{TM}}$ is an automated software tool (Molinari et al., 2014, 2011, 2010), which can be used for monitoring the plaque build-up in carotid and coronary arteries, which can be affected due to coronavirus. AtheroPoint ${ }^{\mathrm{TM}}$ has developed a commercial-grade, completely patented, and 510(K) FDA approved software package called-AtheroEdge ${ }^{\mathrm{TM}}$ 
a

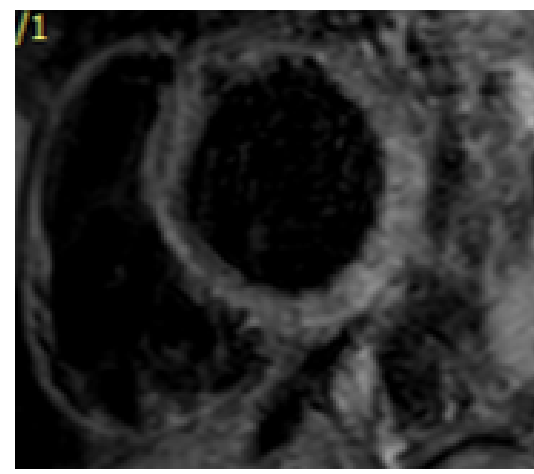

b

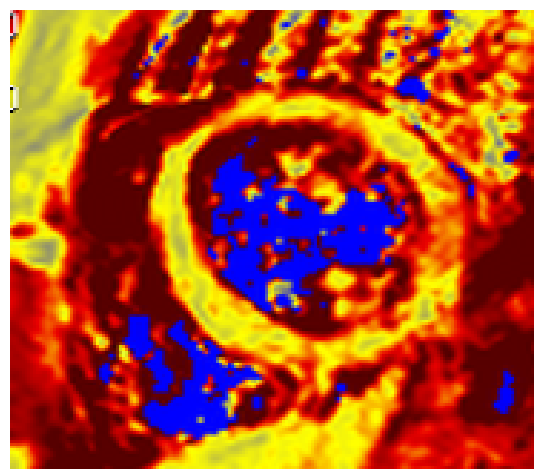

C

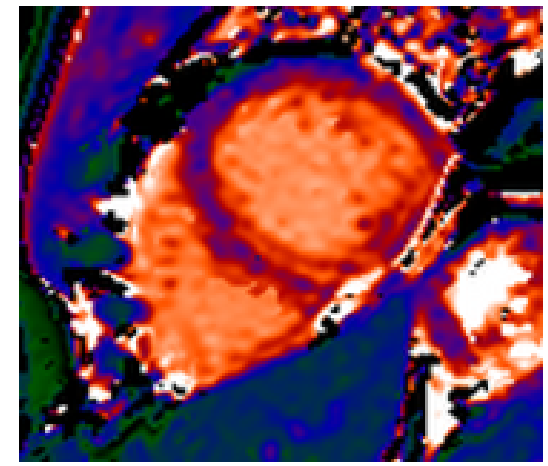

d

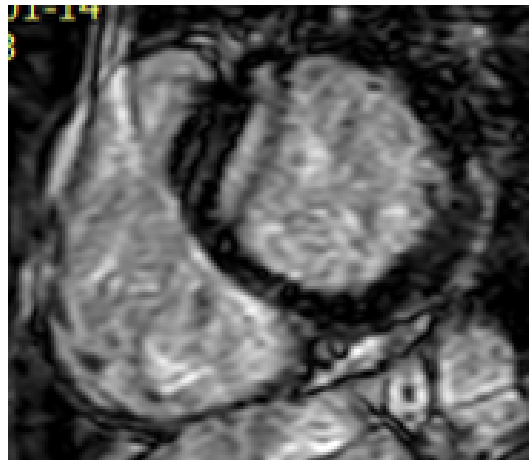

Fig. 4. A patient (27 years old) was admitted to Cagliari University Hospital, Italy with fever and chest pain, without any significant past medical history. The onset of symptomatology dated back about one week. His initial investigation showed elevated troponin levels at laboratory tests. Electrocardiography displayed ST-segment elevation. Echocardiography was normal. A cardiac magnetic performance was performed. T2 STIR (panel a) showed an increased signal in mid-basal inferior and inferior-lateral segments.T2 mapping values (panel b) showed an increased signal in mid-basal inferolateral segment The analysis of T1 mapping (panel c) showed an increase in signal at the same segments. In the sequences acquired later after contrast, an area of sub-epicardial LGE in mid-basal inferior and infero-lateral segments was observed with a concomitant involvement of the adjacent pericardium (panel d) (Courtesy of Luca Saba, AOU, Italy).

1.0 (Cuadrado-Godia et al., 2019, 2018b; Khanna et al., 2019c; Molinari et al., 2014, 2011, 2010; Saba et al., 2012a,c) that can jointly estimate the carotid plaque and wall thickness in carotid ultrasound (CUS) scans. AtheroEdge ${ }^{\mathrm{TM}} 1.0$ automatically computes the five imaging biomarkers, called carotid ultrasound image phenotypes (CUSIP) (Khanna et al., 2019d,b; Molinari et al., 2014). These measurements are used to compute the composite baseline risk of patients called AtheroEdge Composite Risk Score 1.0 (AECRS1.0) (Khanna et al., 2019d,b; Viswanathan et al., 2020b). The AtheroEdge ${ }^{\mathrm{TM}} 1.0$ is a well-validated package against the gold standards such as manual measurements and cross imaging modalities such as MRI and CT (Molinari et al., 2014, 2011; Saba et al., 2018a,b, 2016, 2012c). AtheroEdge ${ }^{\text {TM }} 1.0$ showed a precision of $98.7 \%$ (Krishna Kumar et al., 2017; Saba et al., 2018a). Currently, AtheroEdge ${ }^{\mathrm{TM}} 1.0$ is being used at multiple diagnostic centers around the world for the collection of patient data and more sophisticated CVD/stroke preventive screening development (Liu et al., 2005; Molinari et al., 2014). An epidemiological study of 885 patients in collaboration with the London School of Hygiene and Tropical Medicine (LSHTE), London, UK, was conducted by AtheroPoint ${ }^{\mathrm{TM}}$ LLC to validate the performance of AtheroEdge ${ }^{\mathrm{TM}} 1.0$ software (Ikeda et al., 2013; Molinari et al., 2014). This study showed a $94.7 \%$ agreement between the auto- mated and manual measurements, even in the presence of lowcontrast/low-resolution carotid ultrasound scans (shown in Fig. 5). Furthermore, AtheroEdge ${ }^{\mathrm{TM}} 1.0$ also showed higher accuracy and reproducibility on the low-resolution images (Ikeda et al., 2013).

AtheroPoint ${ }^{\mathrm{TM}}$ showed a strong association between the CUSIP measured using AtheroEdge ${ }^{\mathrm{TM}} 1.0$ and (a) SYNTAX score and (b) Ankle Brachial Index (ABI) (Ikeda et al., 2014, 2013), which are the relevant biomarkers of CVD. Very recently, AtheroEdge ${ }^{\mathrm{TM}} 1.0$ was used to detect the total plaque area (TPA) morphology and geometrical TPA, which are the essential phenotypes of CVD/stroke events (Khanna et al., 2019c; Lucatelli et al., 2016). All these studies projected the use of AECRS1.0 for CUSIP measurements from the common carotid artery. Another study was conducted to show the relationship between the degree of leukoaraiosis (LA), measured as a hemispheric LA volume, in brain MRI and CUSIP measured using AtheroEdge ${ }^{\mathrm{TM}} 1.0$ (Lucatelli et al., 2016).

\subsection{Non-invasive CVD risk assessment beyond "current COVID-19 time"}

The AtheroEdge ${ }^{\mathrm{TM}} 1.0$ software package computed the automated CUSIP from the given CUS scans. Multiple studies have reported the effect of conventional cardiovascular risk factors (CCVRF) on the annual progression of cIMT and plaque area (PA) (Banchhor et al., 2017a; Johri et al., 2013; Osondu et al., 


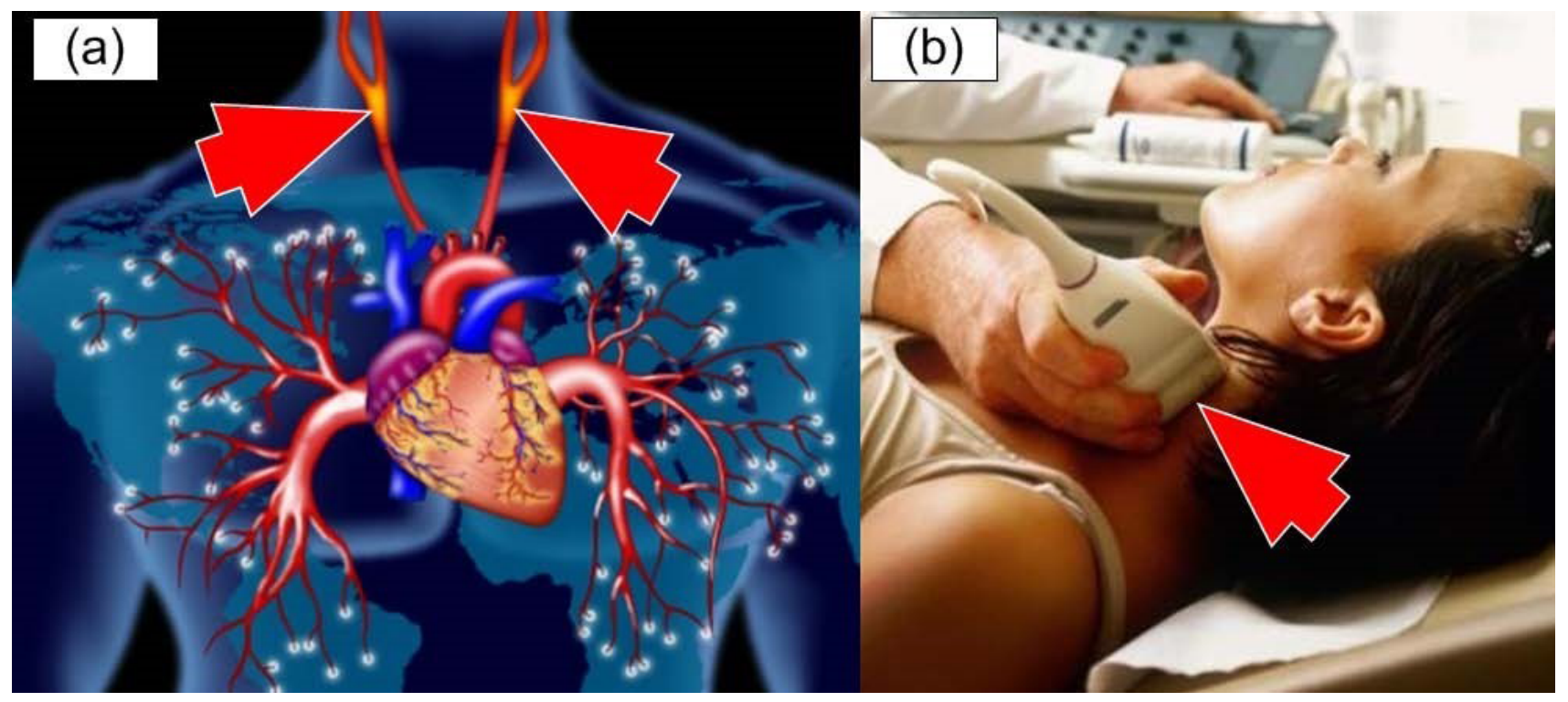

Fig. 5. (a) Carotid artery used as a surrogate of coronary artery disease. (b) Carotid artery scanning (Courtesy of AtheroPoint ${ }^{\mathrm{TM}}$, CA, USA).

2018; Rosvall et al., 2015; Viswanathan et al., 2020a,d). Based on this concept, AtheroPoint ${ }^{\mathrm{TM}}$ LLC, USA, had developed an integrated (office-based biomarkers + laboratory-based biomarkers + carotid ultrasound image-based phenotypes) 10-year image-based $\mathrm{CVD} /$ stroke risk statistical calculator called AtheroEdge ${ }^{\mathrm{TM}}$ 2.0, that computes the AtheroEdge Composite Risk Score 2.0 (AECRS2.0) (Biswas et al., 2020; Johri et al., 2013; Khanna et al., 2019d,b; Saba and Suri, 2013; Suri et al., 2010; Viswanathan et al., 2020b,c) (shown in Fig. 6) for 10-year risk, while AECRS1.0 was for the current risk (without CCVRF). This AECRS2.0 (Johri et al., 2013; Khanna et al., 2019d,b; Suri et al., 2019) has been shown to be stronger than conventional cardiovascular risk calculators (CCVRC) (Conroy, 2003; Goff et al., 2014; Hippisley-Cox et al., 2017; Kothari et al., 2002; D’Agostino et al., 2008; Ridker et al., 2007; Stevens et al., 2001) because AtheroEdge ${ }^{\text {TM }} 2.0$ produced a larger area-under-the-curve (AUC) in comparison to all of the CCRVC. This is due to the integration of laboratory-based biomarkers and office-based biomarkers with current CUSIP. AtheroPoint ${ }^{\mathrm{TM}}$ recently showed that AtheroEdge ${ }^{\mathrm{TM}} 2.0$ could do a better 10-year $\mathrm{CVD} /$ stroke risk estimation when the carotid bulb segment is considered compared to the common carotid artery (Saba et al., 2019). The cumulative ranking of the ten CCVRC demonstrated that QRISK3 was the closest calculator to AtheroEdge ${ }^{\mathrm{TM}}$ 2.0. Additionally, in a study by ranking cardiovascular risk factors, the AECRS 2.0 values ranked at the topmost positions with higher odds ratios compared to the CCVRF (Saba et al., 2019). Since the epithelial dysfunction, which leads to plaque rupture, can be due to SARS-CoV-2 (pathway III-B, Fig. 2), therefore, such calculators can be valuable to track the composite risk on patients who are infected by COVID-19. Note that, although there is no concrete evidence of relationship between myocarditis and atherosclerosis, though the former may lead to CVDs, the risk calculators developed are limited to coronary/carotid imaging biomarkers only. In the future new risk calculator needs to be developed based on vasopasm, myocarditis as well as coronary/carotid imaging.

\subsection{Role of telemedicine with and without AI in COVID-19}

In monitoring, several telemedicine-based approaches have been adapted in support of COVID-19 consultations (Smith et al., 2020; Vidal-Alaball et al., 2020). Telemedicine has been beneficial to authorities in controlling the epidemic situation in India during cholera (Smith et al., 2020), and visceral leishmaniasis (Bhunia et al., 2012) epidemics. In advanced economies, telemedicine, in combination with AI, has used data from social media (Thamman et al., 2020) for successful disease tracking, quantifying disease dynamics, projecting the pandemic curve in high-risk cluster zones, and regulating it from further spread (Bodnar, 2015). For example, the data stream during the Zika epidemic (Daughton and Paul, 2019), Influenza A H1N1 pandemic (Signorini et al., 2011), and Chikungunya epidemic (Mahroum et al., 2018) showed a correlation between the volume of the data streaming using telemedicine and pandemic curve. A similar pattern was also noticed during the current COVID-19 pandemic in China (Li et al., 2020b). A linear regression model was developed to estimate the correlation between a dataset of 115,299 Weibo posts (like Facebook of China) extracted using keywords such as "coronavirus", "epidemic", "Wuhan coronavirus", etc. and the number of active cases in Wuhan and Mainland China. This model showed ten coronavirus cases per 40 posts $\left(\mathrm{R}^{2}=0.621\right.$ and $\left.P<0.001\right)$ in Hubei province, while 10 coronavirus cases per 60 posts $\left(\mathrm{R}^{2}=0.652\right.$ and $P<0.001$ ) in Mainland China (see Fig. 7). This information can help authorities to locate high-risk regional areas where the posts originate in large numbers.

Therefore, the application of AI-based telemedicine can help in building an epidemic model to control pandemics in future smart cities (Wong et al., 2019). Mann et al. (2020) showed that between 2nd march to 14th April 2020 the telemedicine visits increased from 369.1 to 866.8 per day for urgent care and 94.7 daily to 4209.3 ( $4345 \%$ increase) in non-urgent care. Gadzinski et al. (2020) showed the role of telemedicine for COVID-19. The US government has encouraged video visits from any originating location, including their homes, as part of telemedicine-based care 


\begin{tabular}{|c|c|c|c|c|c|c|c|c|c|c|c|}
\hline \multicolumn{4}{|c|}{ Left Common Carotid } & \multicolumn{4}{|c|}{ Right Common Carotid } & \multicolumn{4}{|c|}{ Mean } \\
\hline $\mathrm{SN}$ & Biomarker Type & Color & $\begin{array}{c}\% \\
\text { Contribution }\end{array}$ & SN & Biomarker Type & Color & $\begin{array}{c}\% \\
\text { Contribution }\end{array}$ & SN & Biomarker Type & Color & $\begin{array}{c}\% \\
\text { Contribution }\end{array}$ \\
\hline 1 & eGFR & & 38.58 & 1 & 5 Image Phenotypes & & 58.95 & 1 & 5 Image Phenotypes & & 46.79 \\
\hline 2 & 5 Image Phenotypes & & 34.63 & 2 & eGFR & & 26.03 & 2 & eGFR & & 32.30 \\
\hline 3 & ESR & & 7.32 & 3 & ESR & & 5.41 & 3 & ESR & & 6.37 \\
\hline 4 & HbAlc & & 6.29 & 4 & HbAlc & & 3.13 & 4 & $\mathrm{HbAlc}$ & & 4.71 \\
\hline 5 & Age & & 5.00 & 5 & Age & & 2.51 & 5 & Age & & 3.75 \\
\hline 6 & $\mathrm{BP}$ & & 4.41 & 6 & $\mathrm{BP}$ & & 2.14 & 6 & $\mathrm{BP}$ & & 3.28 \\
\hline 7 & BMI & & 3.01 & 7 & BMI & & 1.46 & 7 & BMI & & 2.23 \\
\hline 8 & Lipids & & 0.75 & 8 & Lipids & & 0.38 & 8 & Lipids & & 0.56 \\
\hline
\end{tabular}

Fig. 6. AECRS system for composite risk score computation. Left: Renal biomarker "eGFR" has the largest contribution to the CVD risk on the left common carotid. Right: Due to plaque, atherosclerosis phenotypes show the highest contribution in the CVD risk on the right common carotid artery (Courtesy AtheroPoint ${ }^{\mathrm{TM}}$, Roseville, CA, USA).

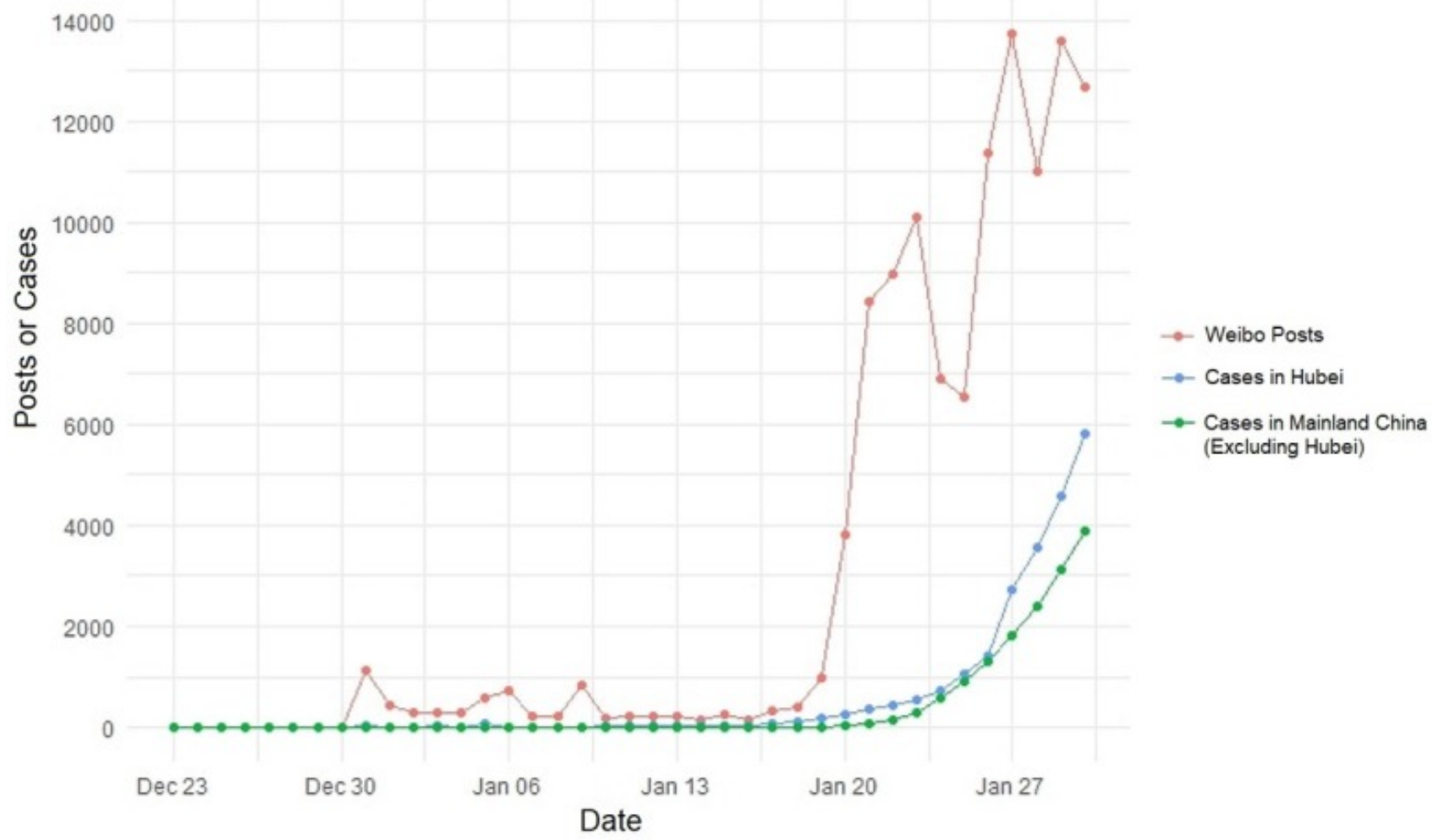

Fig. 7. Linear regression analysis for the COVID-19 pandemic relating to the number of Weibo posts against the actual growth of pandemic (daily coronavirus cases) (Li et al., 2020b).

(Newsroom, 2020). There is a standard CPT code (99213 in the USA) that can be used for reimbursements. In a world where social distancing is the norm, telemedicine combined with $\mathrm{AI}$ in the form of chatbots, wearable devices, etc. can act as a preventive measure for COVID-19 (Wang and Bhatt, 2020).

5.4 Monitoring cycle of the patient during a pandemic
Fig. 8 shows the AI/TM application for tracking patients. There are two major components for COVID19 screening: (i) primary and (ii) secondary. Primary screening: Primary screening is conducted with the help of the robot and AI/TM by questioning basic symptoms while keeping social distance rules. This is already in place in several hospitals around the world. If the COVID-19 symptoms are positive, the patient needs to be quarantined (Q1) 


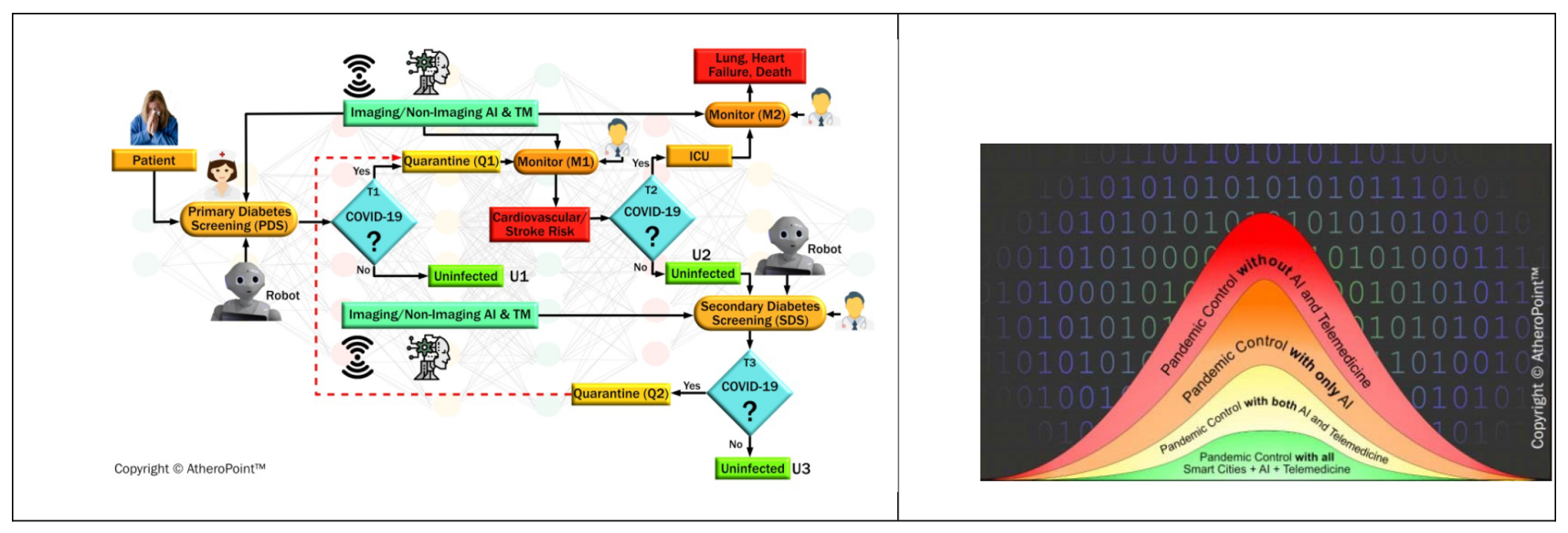

Fig. 8. Role of user-interactive AI, telemedicine, and smart cities on the pandemic (Courtesy of AtheroPoint ${ }^{\mathrm{TM}}$, CA, USA).

or sent home if the patient is uninfected (G1).

The quarantined patient is monitored (M1) continuously using $\mathrm{AI} / \mathrm{TM}$ system and evaluating the CVD risk (shown in RED color). If the COVID-19 tests (T2) are again positive, the patient must be isolated (I) in ICU, and the patient's deteriorating condition must be monitored (M2) using AI/TM system. At this point, the patient would need ventilation and, if worsened, showing the loss of life/death. Secondary screening: If it turns out to be negative, over time, the patient should undergo "secondary screening" using the AI/TM system. COVID-19 test is conducted (T3), and if it turns out to be positive, the feedback loop triggers again (shown as RED dotted line). The secondary infection can be also triggered if the patient is admitted to the hospital (Pacis et al., 2018).

\subsection{Recent AI systems in monitoring and diagnosing COVID-19}

COVID-19 outbreak has led to a flurry of research and development activities in AI-based computer-assistance tools (Suri et al., 2020). The maximum of the research has been directed towards tracking and prediction, diagnosis and prognosis, treatment, and social control. In tracking and prediction, AI models such as the epidemiological SIR model were used to develop containment strategies to reduce the spread rate (Maier and Brockmann, 2020; Song et al., 2020). AI research has led to the development of cheaper and scalable computer aided-tools for diagnosis in the area of medical imaging. A majority of this research has been performed in the area of characterization of COVID-19 infected lung scans (Butt et al., 2020; Harmon et al., 2020; Ilyas et al., 2020; Inciardi et al., 2020a; Jamshidi et al., 2020; Ozsahin et al., 2020; F. Shi et al., 2020a) and mortality risk of patients (Jiang et al., 2020; Yan et al., 2020a). AI has also the potential of new drug discovery for COVID-19 as shown by recent works (Beck et al., 2020; Stebbing et al., 2020). Applications have been shown to control crowds and implementing social distancing by collecting heat signatures through infrared cameras in public places (Chun, 2020), and information update about medical conditions (Hense et al., 2020).

\section{Recommendation for handling pandemics using AI-based platforms}

The following are the recommendations of this universal voice on the role of artificial intelligence in cardiovascular risk assessment during COVID times and beyond.

\subsection{Disease-specific AI platforms}

Patients with a specific disease (say diabetes, hypertension, cancer, ARDS, and neurological disorder) must be tracked to obtain biomarkers of a specific disease for training AI platforms specific to the "type of disease". The management of different diseases comes from different medical departments. Therefore, the risk stratification for different disease points can be based on different AI-platforms. For patients who are having multiple diseases, we will need classification methods that can handle multiple diseases, and such AI-platform will be a fused AI-platform that can accept patients having multiple diseases. This is since AI (especially deep learning) will be able to handle the nonlinear variations dynamically. All the above requires validation using multimodality imaging utilizing registration models (Guo et al., 2006; Narayanan et al., 2009; Suri et al., 2005).

\subsection{Cohort sizes}

A large cohort needs to be built for these patient databases specific to the disease. This can be a global endeavor for future tracking, diagnosis, and prognosis of the pandemic. Although DL requires a large cohort for training, in some cases, where enough training data may not be available for classifying specific diseases (Gajardo et al., 2020), AI programmers use techniques such as data augmentation (DA) (Mikolajczyk and Grochowski, 2018; Shorten and Khoshgoftaar, 2019) and transfer learning (TL) (Huynh et al., 2016; Tan et al., 2018). In DA, the main aim is at building artificial data by transforming existing data samples to help the model train from large intraclass variances. In TL, the knowledge in the form of trained AI model parameters on relatable diseases is used to characterize the specific ones.

\subsection{A note on personalized medicine using AI-based systems}

The advent of big data for medical health records and patient information has given a promising expectation for a faster and accurate diagnosis and treatment (Dilsizian and Siegel, 2014; Gruson et al., 2020; Kagiyama et al., 2019; Krittanawong et al., 2020). AI-models are therefore required to "mine" exact information from this data volume to assist clinicians in performing real time diagnostic and therapeutic recommendations. Hence it is not uncommon that AI-based studies performing diagnostic and even therapeutic services for cardiovascular diseases. In a recent work, 


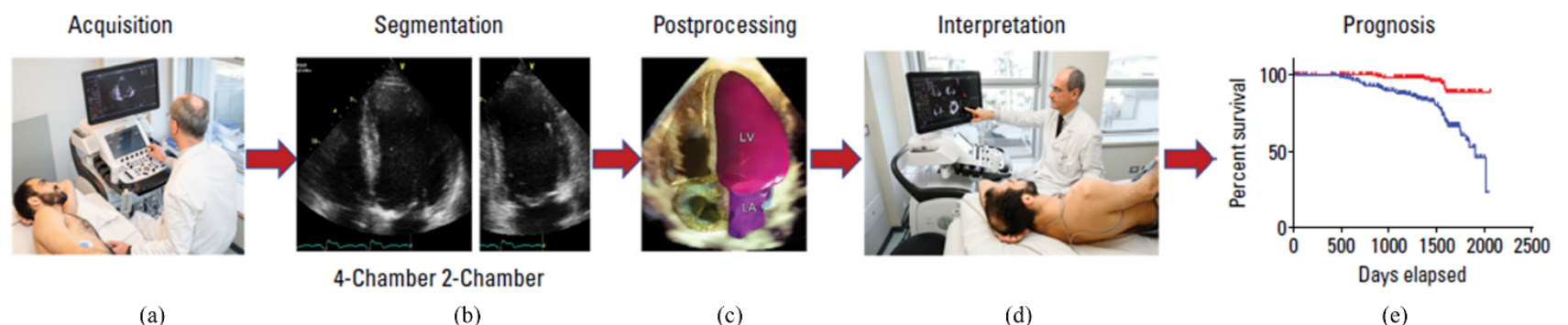

(a)

(b)

(c)

(d)

(e)

Fig. 9. (a) Echocardiographic scan taken, (b) AI-based LV segmentation, (c) post-processing, (d) clinical interpretation, and (e) risk estimation and prognosis (Courtesy of (Badano, 2020)).

an AI-based study segmented the plaque volume from the carotid artery ultrasound scans and estimated the CVD risk by measuring the cIMT (Biswas et al., 2018). In another work by the same group, the AI model was used to compute the stenosis and estimate the CVD risk in the same cohort (Saba et al., 2019b). Another example of personalized approach to heart care is shown in Fig. 9 (Badano, 2020). The AI-based approaches can help in fourout-of-five stages i.e, segmentation, post-processing, interpretation and risk estimation and prognosis with each stage using a separate model. Overall, it is projected that AI-based diagnosis and treatment will lead to effective precision care and better monitoring outcomes.

\subsection{Biobank developments}

There is a clear need to build universal biobanks that can be shared with genuine institutions involved in AI platform developments. There needs to be a trail of documents involved in obtaining such biobanks for research and commercial developments for the benefit of humanity. Blockchain models can be adapted to improve data sharing.

\subsection{Telemedicine embedded with AI}

Advanced telemedicine applications with "embed A" would be more beneficial for patient monitoring.

The input data can be fed in AI-based solutions for better clinical oriented results via remote access.

\subsection{Smart city developments with Blockchain, telemedicine, and AI}

With advanced AI developments and Blockchain technologies, cities can opt for joining the model for smart city developments using to avoid the worsening of catastrophes. A representative diagram of pandemic risk management using AI, telemedicine, and smart cities is shown in Fig. 7.

\section{Conclusions}

This perspective presented the role of AI in medicine and specifically throwing light on the area of diagnosis and monitoring strategies for heart injury due to COVID-19. Imaging and non-imaging biomarkers can be used for machine learning and deep learning models. Non-invasive cardiovascular surrogate markers may be useful for early diagnosis of acute cardiovascular and thromboembolic complications, as well as for monitoring and management of heart disease in such patients during COVID-19 times or beyond, such as five or ten-year risk assessment systems which will be increasingly important for the growing number of
COVID-19 survivors. The study also presents recommendations for efficiently utilizing the AI models during the current and future pandemics.

\section{Author contributions}

(I) Conception and design: Jasjit S. Suri, Anudeep Puvvala, Misha Majhail, Mainak Biswas, Ankush Jamthikar, (II) Administrative support: Jasjit S. Suri,Luca Saba, Inder M Singh, Ronald Oberleitner, (III) Manuscript writing: Jasjit S. Suri, Anudeep Puvvala, Misha Majhail, Mainak Biswas, Ankush Jamthikar, Amer M. Johri, Saurabh Srivastava, George D Kitas, (IV) Proofreading: All authors, (V) Final approval of manuscript: All authors.

\section{Acknowledgements}

We would like to express my gratitude to all those who helped me during the writing of this manuscript.

\section{Conflict of Interest}

Dr. Jasjit Suri is affiliated to AtheroPoint ${ }^{\mathrm{TM}}$, focused in the area of stroke and cardiovascular imaging.

Dr. Vijay Nambi discloses the following relationships - (i) site PI study sponsored by Merck (complete), Amgen (to start); (ii) provisional patent along with Roche and Baylor College of Medicine for the use of biomarkers in prediction of heart failure; (iii) Dr. Nambi is supported by VA MERIT grant.

Dr. Deepak L. Bhatt discloses the following relationships Advisory Board: Cardax, CellProthera, Cereno Scientific, Elsevier Practice Update Cardiology, Level Ex, Medscape Cardiology, MyoKardia, PhaseBio, PLx Pharma, Regado Biosciences; Board of Directors: Boston VA Research Institute, Society of Cardiovascular Patient Care, TobeSoft; Chair: American Heart Association Quality Oversight Committee; Data Monitoring Committees: Baim Institute for Clinical Research (formerly Harvard Clinical Research Institute, for the PORTICO trial, funded by St. Jude Medical, now Abbott), Cleveland Clinic (including for the ExCEED trial, funded by Edwards), Contego Medical (Chair, PERFORMANCE 2), Duke Clinical Research Institute, Mayo Clinic, Mount Sinai School of Medicine (for the ENVISAGE trial, funded by Daiichi Sankyo), Population Health Research Institute; Honoraria: American College of Cardiology (Senior Associate Editor, Clinical Trials and News, ACC.org; Vice-Chair, ACC Accreditation Committee), Baim Institute for Clinical Research (formerly Harvard Clinical Research Institute; RE-DUAL PCI clin- 
ical trial steering committee funded by Boehringer Ingelheim; AEGIS-II executive committee funded by CSL Behring), Belvoir Publications (Editor in Chief, Harvard Heart Letter), Canadian Medical and Surgical Knowledge Translation Research Group (clinical trial steering committees), Duke Clinical Research Institute (clinical trial steering committees, including for the PRONOUNCE trial, funded by Ferring Pharmaceuticals), HMP Global (Editor in Chief, Journal of Invasive Cardiology), Journal of the American College of Cardiology (Guest Editor; Associate Editor), K2P (Co-Chair, interdisciplinary curriculum), Level Ex, Medtelligence/ReachMD (CME steering committees), MJH Life Sciences, Population Health Research Institute (for the COMPASS operations committee, publications committee, steering committee, and USA national co-leader, funded by Bayer), Slack Publications (Chief Medical Editor, Cardiology Today's Intervention), Society of Cardiovascular Patient Care (Secretary/Treasurer), WebMD (CME steering committees); Other: Clinical Cardiology (Deputy Editor), NCDR-ACTION Registry Steering Committee (Chair), VA CART Research and Publications Committee (Chair); Research Funding: Abbott, Afimmune, Amarin, Amgen, AstraZeneca, Bayer, Boehringer Ingelheim, Bristol-Myers Squibb, Cardax, Chiesi, CSL Behring, Eisai, Ethicon, Ferring Pharmaceuticals, Forest Laboratories, Fractyl, Idorsia, Ironwood, Ischemix, Lexicon, Lilly, Medtronic, MyoKardia, Pfizer, PhaseBio, PLx Pharma, Regeneron, Roche, Sanofi, Synaptic, The Medicines Company; Royalties: Elsevier (Editor, Cardiovascular Intervention: A Companion to Braunwald's Heart Disease); Site CoInvestigator: Biotronik, Boston Scientific, CSI, St. Jude Medical (now Abbott), Svelte; Trustee: American College of Cardiology; Unfunded Research: FlowCo, Merck, Novo Nordisk, Takeda.

Submitted: November 02, 2020

Revised: December 03, 2020

Accepted: December 08, 2020

Published: December 30, 2020

\section{References}

Acharya, R., Ng, Y. E. and Suri, J. S. (2008) Image modeling of the human eye. Artech House.

Acharya, U. R., Mookiah, M. R., Vinitha Sree, S., Afonso, D., Sanches, J., Shafique, S., Nicolaides, A., Pedro, L. M., Fernandes, E. F. J. and Suri, J. S. (2013a) Atherosclerotic plaque tissue characterization in 2D ultrasound longitudinal carotid scans for automated classification: a paradigm for stroke risk assessment. Medical and Biological Engineering and Computing 51, 513-523.

Acharya, U. R., Faust, O., S., V. S., Alvin, A. P. C., Krishnamurthi, G., Seabra, J. C. R., Sanches, J. and Suri, J. S. (2013b) Understanding symptomatology of atherosclerotic plaque by image-based tissue characterization. Computer Methods and Programs in Biomedicine 110, 6675.

Acharya, U. R., Molinari, F., Sree, S. V., Swapna, G., Saba, L., Guerriero, S. and Suri, J. S. (2015) Ovarian tissue characterization in ultrasound. Technology in Cancer Research \& Treatment 14, 251-261.

Acharya, U. R., Sree, S. V., Saba, L., Molinari, F., Guerriero, S. and Suri, J. S. (2013c) Ovarian tumor characterization and classification using ultrasound-a new online paradigm. Journal of Digital Imaging 26, 544553.

Akhmerov, A. and Marbán, E. (2020) COVID-19 and the heart. Circulation Research 126, 1443-1455.

Alakwaa, W., Nassef, M. and Badr, A. (2017) Lung cancer detection and classification with 3D convolutional neural network (3D-CNN). International Journal of Advanced Computer Science and Applications 8, 409-417.
Alhogbani, T. (2016) Acute myocarditis associated with novel Middle east respiratory syndrome coronavirus. Annals of Saudi Medicine 36, 78-80.

Alimadadi, A., Aryal, S., Manandhar, I., Munroe, P. B., Joe, B. and Cheng, X. (2020) Artificial intelligence and machine learning to fight COVID19. Physiological Genomics 52, 200-202.

Álvarez-Machancoses, Ó., Galiana, E. J. D., Cernea, A., de la Viña, J. F. and Fernández-Martínez, J. L. (2020) On the role of artificial intelligence in genomics to enhance precision medicine. Pharmacogenomics and Personalized Medicine 13, 105-119.

Angermueller, C., Pärnamaa, T., Parts, L. and Stegle, O. (2016) Deep learning for computational biology. Molecular Systems Biology 12, 878.

Asch, F. M., Poilvert, N., Abraham, T., Jankowski, M., Cleve, J., Adams, M., Romano, N., Hong, H., Mor-Avi, V., Martin, R. P. and Lang, R. M. (2019) Automated echocardiographic quantification of left ventricular ejection fraction without volume measurements using a machine learning algorithm mimicking a human expert. Circulation: Cardiovascular Imaging 12, e009303.

Attia, Z. I., Kapa, S., Noseworthy, P. A., Lopez-Jimenez, F. and Friedman, P. A. (2020) Artificial intelligence ECG to detect left ventricular dysfunction in COVID-19: a case series. Mayo Clinic Proceedings 95, 2464-2466.

Avendi, M. R., Kheradvar, A. and Jafarkhani, H. (2016) A combined deeplearning and deformable-model approach to fully automatic segmentation of the left ventricle in cardiac MRI. Medical Image Analysis 30 , 108-119.

Badano, L. (2020) Artificial intelligence and cardiovascular imaging. A win-win combination. The Anatolian Journal of Cardiology 24, 214223.

Bale, R. (2020) Trafficked pangolins can carry coronaviruses closely related to pandemic strain. National Geographic-Animals desk:Coronavirus Coverage National Geographic.

Banchhor, S. K., Londhe, N. D., Araki, T., Saba, L., Radeva, P., Laird, J. R. and Suri, J. S. (2017a) Wall-based measurement features provides an improved IVUS coronary artery risk assessment when fused with plaque texture-based features during machine learning paradigm. Computers in Biology and Medicine 91, 198-212.

Banchhor, S. K. (2017b) Relationship between automated coronary calcium volumes and a set of manual coronary lumen volume, vessel volume and atheroma volume in japanese diabetic cohort. Journal of Clinical and Diagnostic Research 11, TC09-TC14.

Bansal, M. (2020) Cardiovascular disease and COVID-19. Diabetes \& Metabolic Syndrome 14, 247-250.

Barnes, B. J., Adrover, J. M., Baxter-Stoltzfus, A., Borczuk, A., CoolsLartigue, J., Crawford, J. M., Daßler-Plenker, J., Guerci, P., Huynh, C., Goodman Cancer Research Centre, McGill University, Montreal, Canada, Knight, J. S., Loda, M., Looney, M. R., McAllister, F., Rayes, R., Renaud, S., Rousseau, S., Salvatore, S., Schwartz, R. E., Spicer, J. D., Yost, C. C., Weber, A., Zuo, Y. and Egeblad, M. (2020) Targeting potential drivers of COVID-19: Neutrophil extracellular traps. Journal of Experimental Medicine 217, e20200652.

Beck, B. R., Shin, B., Choi, Y., Park, S. and Kang, K. (2020) Predicting commercially available antiviral drugs that may act on the novel coronavirus (SARS-CoV-2) through a drug-target interaction deep learning model. Computational and Structural Biotechnology Journal 18, 784790.

Bernstein, K. E. (2002) Two ACEs and a heart. Nature 417, 799-801.

Bhunia, G. S., Kesari, S., Chatterjee, N., Kumar, V. and Das, P. (2012) Telehealth: a perspective approach for visceral leishmaniasis (kalaazar) control in India. Pathogens and Global Health 106, 150-158.

Bikdeli, B., Madhavan, M. V., Jimenez, D., Chuich, T., Dreyfus, I., Driggin, E., Nigoghossian, C. D., Ageno, W., Madjid, M., Guo, Y., et al. (2020) COVID-19 and thrombotic or thromboembolic disease: implications for prevention, antithrombotic therapy, and follow-up. Journal of the American College of Cardiology 75, 2950-2973.

Bishop, C. M. (2006) Pattern recognition and machine learning. Springer. Biswas, M., Kuppili, V., Araki, T., Edla, D. R., Godia, E. C., Saba, L., Suri, H. S., Omerzu, T., Laird, J. R., Khanna, N. N., Nicolaides, A. and Suri, J. S. (2018) Deep learning strategy for accurate carotid intima- 
media thickness measurement: an ultrasound study on Japanese diabetic cohort. Computers in Biology and Medicine 98, 100-117.

Biswas, M., Kuppili, V., Edla, D. R., Suri, H. S., Saba, L., Marinhoe, R. T., Sanches, J. M. and Suri, J. S. (2018) Symtosis: a liver ultrasound tissue characterization and risk stratification in optimized deep learning paradigm. Computer Methods and Programs in Biomedicine 155, 165177.

Biswas, M., Kuppili, V., Saba, L., Edla, D. R., Suri, H. S., CuadradoGodia, E., Laird, J. R., Marinhoe, R. T., Sanches, J. M., Nicolaides, A. and Suri, J. S. (2019) State-of-the-art review on deep learning in medical imaging. Frontiers in Bioscience 24, 392-426.

Biswas, M., Saba, L., Chakrabartty, S., Khanna, N. N., Song, H., Suri, H. S., Sfikakis, P. P., Mavrogeni, S., Viskovic, K. and Laird, J. R. (2020) Two-stage artificial intelligence model for jointly measurement of atherosclerotic wall thickness and plaque burden in carotid ultrasound: a screening tool for cardiovascular/stroke risk assessment. Computers in Biology and Medicine 123, 103847.

Blauwet, L. A. and Cooper, L. T. (2010) Myocarditis. Progress in Cardiovascular Diseases 52, 274-288.

Bodnar, T. J. (2015) Data Science with Social Media for Epidemiology and Public Health [Electronic Theses and Dissertations for Graduate School]. Penn State.

Boi, A., Jamthikar, A. D., Saba, L., Gupta, D., Sharma, A., Loi, B., Laird, J. R., Khanna, N. N. and Suri, J. S. (2018) A survey on coronary atherosclerotic plaque tissue characterization in intravascular optical coherence tomography. Current Atherosclerosis Reports 20, 33.

Butt, C., Gill, J., Chun, D. and Babu, B. A. (2020) Deep learning system to screen coronavirus disease 2019 pneumonia. Applied Intelligence 22, $1-7$.

Cai, G. (2020) Bulk and single-cell transcriptomics identify tobacco-use disparity in lung gene expression of ACE2, the receptor of 2019-nCov. MedRxiv (in press).

Carneiro, G. and Nascimento, J. C. (2013) Combining multiple dynamic models and deep learning architectures for tracking the left ventricle endocardium in ultrasound data. IEEE Transactions on Pattern Analysis and Machine Intelligence 35, 2592-2607.

Cau, R., Bassareo, P. P., Mannelli, L., Suri, J. S. and Saba, L. (2020) Imaging in COVID-19-related myocardial injury. The International Journal of Cardiovascular Imaging (in press).

CDC. (2020) Coronavirus Disease 2019 (COVID-19)-Global COVID-19 World Map. Centers for Disease Control and Prevention CDC.

Chen, L., Li, X., Chen, M., Feng, Y. and Xiong, C. (2020) The ACE2 expression in human heart indicates new potential mechanism of heart injury among patients infected with SARS-CoV-2. Cardiovascular Research 116, 1097-1100.

Chen, N., Zhou, M., Dong, X., Qu, J., Gong, F., Han, Y., Qiu, Y., Wang, J., Liu, Y. and Wei, Y. (2020b) Epidemiological and clinical characteristics of 99 cases of 2019 novel coronavirus pneumonia in Wuhan, China: a descriptive study. The Lancet 395, 507-513.

Chun, A. (2020) In a time of coronavirus, Chinas investment in AI is paying off in a big way. South China Morning Post.

Clerkin, K. J., Fried, J. A., Raikhelkar, J., Sayer, G., Griffin, J. M., Masoumi, A., Jain, S. S., Burkhoff, D., Kumaraiah, D., Rabbani, L., Schwartz, A. and Uriel, N. (2020) COVID-19 and cardiovascular disease. Circulation 141, 1648-1655.

Conroy, R. (2003) Estimation of ten-year risk of fatal cardiovascular disease in Europe: the SCORE project. European Heart Journal 24, $987-$ 1003.

Cuadrado-Godia, E., Dwivedi, P., Sharma, S., Ois Santiago, A., Roquer Gonzalez, J., Balcells, M., Laird, J., Turk, M., Suri, H. S., Nicolaides, A., Saba, L., Khanna, N. N. and Suri, J. S. (2018a) Cerebral small vessel disease: a review focusing on pathophysiology, biomarkers, and machine learning strategies. Journal of Stroke 20, 302-320.

Cuadrado-Godia, E., Jamthikar, A. D., Gupta, D., Khanna, N. N., Araki, T., Maniruzzaman, M., Saba, L., Nicolaides, A., Sharma, A., Omerzu, T., Suri, H. S., Gupta, A., Mavrogeni, S., Turk, M., Laird, J. R., Protogerou, A., Sfikakis, P., Kitas, G. D., Viswanathan, V. and Suri, J. S. (2019) Ranking of stroke and cardiovascular risk factors for an optimal risk calculator design: logistic regression approach. Computers in
Biology and Medicine 108, 182-195.

Cuadrado-Godia, E., Maniruzzaman, M., Araki, T., Puvvula, A., Jahanur Rahman, M., Saba, L., Suri, H. S., Gupta, A., Banchhor, S. K., Teji, J. S., Omerzu, T., Khanna, N. N., Laird, J. R., Nicolaides, A., Mavrogeni, S., Kitas, G. D. and Suri, J. S. (2018b) Morphologic TPA (mTPA) and composite risk score for moderate carotid atherosclerotic plaque is strongly associated with $\mathrm{HbA} 1 \mathrm{c}$ in diabetes cohort. Computers in Biology and Medicine 101, 128-145.

Cui, J., Li, F. and Shi, Z.-L. (2019) Origin and evolution of pathogenic coronaviruses. Nature Reviews Microbiology 17, 181-192.

Daughton, A. R. and Paul, M. J. (2019) Identifying protective health behaviors on twitter: observational study of travel advisories and zika virus. Journal of Medical Internet Research 21, e13090.

de Wit, E., van Doremalen, N., Falzarano, D. and Munster, V. J. (2016) SARS and MERS: recent insights into emerging coronaviruses. Nature Reviews Microbiology 14, 523-534.

Díaz, J. J. S. (2020) Chapter 13 - Artificial intelligence in cardiovascular medicine: Applications in the diagnosis of infarction and prognosis of heart failure. In, Díaz, J. J. S. (eds.) Artificial Intelligence in Precision Health (pp. 313-328). Massachusetts: Academic Press.

Dilsizian, S. E. and Siegel, E. L. (2014) Artificial intelligence in medicine and cardiac imaging: harnessing big data and advanced computing to provide personalized medical diagnosis and treatment. Current Cardiology Reports 16, 441.

Dong, B., Zhang, C., Feng, J. B., Zhao, Y. X., Li, S. Y., Yang, Y. P., Dong, Q. L., Deng, B. P., Zhu, L. and Yu, Q. T. (2008) Overexpression of ACE2 enhances plaque stability in a rabbit model of atherosclerosis Arteriosclerosis, Thrombosis, and Vascular Biology 28, 1270-1276.

Dong, D., Tang, Z., Wang, S., Hui, H., Gong, L., Lu, Y., Xue, Z., Liao, H., Chen, F., Yang, F., Jin, R., Wang, K., Liu, Z., Wei, J., Mu, W., Zhang, H., Jiang, J., Tian, J. and Li, H. (2020) The role of imaging in the detection and management of COVID-19: a review. IEEE Reviews in Biomedical Engineering (in press).

Donoghue, M., Hsieh, F., Baronas, E., Godbout, K., Gosselin, M., Stagliano, N., Donovan, M., Woolf, B., Robison, K., Jeyaseelan, R., Breitbart, R. E. and Acton, S. (2000) A novel angiotensin-converting enzyme-related carboxypeptidase (ACE2) converts angiotensin I to angiotensin 1-9. Circulation Research 87, E1-9.

Driggin, E., Madhavan, M. V., Bikdeli, B., Chuich, T., Laracy, J., BiondiZoccai, G., Brown, T. S., Der Nigoghossian, C., Zidar, D. A. and Haythe, J. (2020) Cardiovascular considerations for patients, health care workers, and health systems during the COVID-19 pandemic. Journal of the American College of Cardiology 75, 2352-2371.

Eder, S. (2020) 430,000 people have traveled from China to U.S. since Coronavirus surfaced. The New York Times, 1.

Edmonds, L. (2020) 430,000 people have traveled from China to the US since the COVID-19 outbreak appeared - including nearly 40,000 who arrived after President Trump imposed travel restrictions. Mail Online.

El-Baz, A. and Suri, J. S. (2011) Lung imaging and computer aided diagnosis. United States: CRC Press.

El-Baz, A. (2018) Cardiovascular Imaging and Image Analysis.

Fadini, G. P., Morieri, M. L., Longato, E. and Avogaro, A. (2020) Prevalence and impact of diabetes among people infected with SARS-CoV-2. Journal of Endocrinological Investigation 43, 867-869.

Fang, L., Karakiulakis, G. and Roth, M. (2020) Are patients with hypertension and diabetes mellitus at increased risk for COVID-19 infection? The Lancet Respiratory Medicine 8, e21.

Ferreira, V. M., Schulz-Menger, J., Holmvang, G., Kramer, C. M., Carbone, I., Sechtem, U., Kindermann, I., Gutberlet, M., Cooper, L. T., Liu, P. and Friedrich, M. G. (2018) Cardiovascular magnetic resonance in nonischemic myocardial inflammation. Journal of the American College of Cardiology 72, 3158-3176.

Filardi, T. and Morano, S. (2020) COVID-19: is there a link between the course of infection and pharmacological agents in diabetes? Journal of Endocrinological Investigation 43, 1053-1060.

Flach, P. A. (2001) On the state of the art in machine learning: a personal review. Artificial Intelligence 131, 199-222.

Gadzinski, A. J., Gore, J. L., Ellimoottil, C., Odisho, A. Y. and Watts, K. L. (2020) Implementing telemedicine in response to the COVID-19 
pandemic. Journal of Urology 204, 14-16.

Gajardo, A. I., Henríquez, F. and Llancaqueo, M. (2020) Big data, social determinants of coronary heart disease and barriers for data access. European Journal of Preventive Cardiology 19, 204748732092236.

Ganasegeran, K. and Abdulrahman, S. A. (2020) Artificial intelligence applications in tracking health behaviors during disease epidemics. $\mathrm{Hu}$ man Behaviour Analysis Using Intelligent Systems 28, 141-155.

Gasso, L. F., Melon, N. M. M., Cebada, F. S., Solis, J. and Tejada, J. G. (2020) Multivessel spontaneous coronary artery dissection presenting in a patient with severe acute SARS-CoV-2 respiratory infection. European Heart Journal 41, 3100-3101.

Geng, Y.-J., Wei, Z.-Y., Qian, H.-Y., Huang, J., Lodato, R. and Castriotta, R. J. (2020) Pathophysiological characteristics and therapeutic approaches for pulmonary injury and cardiovascular complications of coronavirus disease 2019. Cardiovascular Pathology 47, 107228.

Genovese, D., Rashedi, N., Weinert, L., Narang, A., Addetia, K., Patel, A. R., Prater, D., Gonçalves, A., Mor-Avi, V. and Lang, R. M. (2019) Machine learning-based three-dimensional echocardiographic quantification of right ventricular size and function: validation against cardiac magnetic resonance. Journal of the American Society of Echocardiography 32, 969-977.

Ghorbani, A., Ouyang, D., Abid, A., He, B., Chen, J. H., Harrington, R. A., Liang, D. H., Ashley, E. A. and Zou, J. Y. (2020) Deep learning interpretation of echocardiograms. NPJ Digital Medicine 3, 10.

Goff, D. C., Lloyd-Jones, D. M., Bennett, G., Coady, S., D'agostino, R. B. Gibbons, R., Greenland, P., Lackland, D. T., Levy, D. and O'donnell, C. J. (2014) 2013 ACC/AHA guideline on the assessment of cardiovascular risk: a report of the American College of Cardiology/American Heart Association Task Force on Practice Guidelines. Journal of the American College of Cardiology 63, 2935-2959.

Gruson, D., Bernardini, S., Dabla, P. K., Gouget, B. and Stankovic, S. (2020) Collaborative AI and Laboratory Medicine integration in precision cardiovascular medicine. Clinica Chimica Acta 509, 67-71.

Guan, W., Ni, Z., Hu, Y., Liang, W., Ou, C., He, J., Liu, L., Shan, H., Lei, C., Hui, D. S. C., et al. (2020) Clinical characteristics of Coronavirus disease 2019 in China. New England Journal of Medicine 382, 17081720.

Guo, T., Fan, Y., Chen, M., Wu, X., Zhang, L., He, T., Wang, H., Wan, J., Wang, X. and Lu, Z. (2020) Cardiovascular implications of fatal outcomes of patients with coronavirus disease 2019 (COVID-19). JAMA Cardiology 5, 811-818.

Guo, Y., Sivaramakrishna, R., Lu, C., Suri, J. S. and Laxminarayan, S. (2006) Breast image registration techniques: a survey. Medical \& Biological Engineering \& Computing 44, 15-26.

Hampel, H., Williams, C., Etcheto, A., Goodsaid, F., Parmentier, F., Sallantin, J., Kaufmann, W. E., Missling, C. U. and Afshar, M. (2020) A precision medicine framework using artificial intelligence for the identification and confirmation of genomic biomarkers of response to an Alzheimer's disease therapy: analysis of the blarcamesine (ANAVEX2-73) Phase 2a clinical study. Alzheimer's \& Dementia: Translational Research \& Clinical Interventions 6, e12013.

Harmon, S. A., Sanford, T. H., Xu, S., Turkbey, E. B., Roth, H., Xu, Z., Yang, D., Myronenko, A., Anderson, V. and Amalou, A. (2020) Artificial intelligence for the detection of COVID-19 pneumonia on chest CT using multinational datasets. Nature Communications 11, 1-7.

Hassanzadeh, P., Atyabi, F. and Dinarvand, R. (2019) The significance of artificial intelligence in drug delivery system design. Advanced Drug Delivery Reviews 151-152, 169-190.

Hejjaji, V., Tang, Y., Jones, P., Ellerbeck, E., Pacheco, C., Malik, A. O., Chan, P. S., Spertus, J. and Arnold, S. V. (2020) Abstract P249: association between cardiovascular event type and smoking cessation rates among outpatients with atherosclerotic cardiovascular disease: insights from the ncdr pinnacle registry. Circulation 141, AP249-AP249.

Hinojar, R., Nagel, E. and Puntmann, V. O. (2016) Advances in cardiovascular MRI using quantitative tissue characterisation techniques: focus on myocarditis. European Cardiology 11, 20-24.

Hippisley-Cox, J., Coupland, C. and Brindle, P. (2017) Development and validation of QRISK3 risk prediction algorithms to estimate future risk of cardiovascular disease: prospective cohort study. British Medical
Journal 357, j2099.

Hoffmann, M., Kleine-Weber, H., Schroeder, S., Krüger, N., Herrler, T., Erichsen, S., Schiergens, T. S., Herrler, G., Wu, N., Nitsche, A., Müller M. A., Drosten, C. and Pöhlmann, S. (2020) SARS-CoV-2 cell entry depends on ACE2 and TMPRSS2 and is blocked by a clinically proven protease inhibitor. Cell 181, 271-280.e8.

Huang, C., Wang, Y., Li, X., Ren, L., Zhao, J., Hu, Y., Zhang, L., Fan, G., Xu, J., Gu, X., Cheng, Z., Yu, T., Xia, J., Wei, Y., Wu, W., Xie, X., Yin, W., Li, H., Liu, M., Xiao, Y., Gao, H., Guo, L., Xie, J., Wang, G., Jiang, R., Gao, Z., Jin, Q., Wang, J. and Cao, B. (2020) Clinical features of patients infected with 2019 novel coronavirus in Wuhan, China. The Lancet 395, 497-506.

Huang, Y., Tan, C., Wu, J., Chen, M., Wang, Z., Luo, L., Zhou, X., Liu, X., Huang, X., Yuan, S., Chen, C., Gao, F., Huang, J., Shan, H. and Liu, J. (2020) Impact of coronavirus disease 2019 on pulmonary function in early convalescence phase. Respiratory Research 21, 163.

Hubel, D. H. and Wiesel, T. N. (1962) Receptive fields, binocular interaction and functional architecture in the cat's visual cortex. The Journal of Physiology 160, 106-154.

Huet, F., Prieur, C., Schurtz, G., Gerbaud, E., Manzo-Silberman, S., Vanzetto, G., Elbaz, M., Tea, V., Mercier, G., Lattuca, B., Duflos, C. and Roubille, F. (2020) One train may hide another: acute cardiovascular diseases could be neglected because of the COVID-19 pandemic. Archives of Cardiovascular Diseases 113, 303-307.

Huynh, B. Q., Li, H. and Giger, M. L. (2016) Digital mammographic tumor classification using transfer learning from deep convolutional neural networks. Journal of Medical Imaging 3, 034501.

Ikeda, N., Araki, T., Sugi, K., Nakamura, M., Deidda, M., Molinari, F., Meiburger, K. M., Acharya, U. R., Saba, L., Bassareo, P. P., Di Martino, M., Nagashima, Y., Mercuro, G., Nakano, M., Nicolaides, A. and Suri, J. S. (2014) Ankle-brachial index and its link to automated carotid ultrasound measurement of intima-media thickness variability in 500 Japanese coronary artery disease patients. Current Atherosclerosis Reports 16, 393.

Ikeda, N., Kogame, N., Iijima, R., Nakamura, M. and Sugi, K. (2013) Impact of carotid artery ultrasound and ankle-brachial index on prediction of severity of SYNTAX score. Circulation Journal 77, 712-716.

Ilyas, M., Rehman, H. and Naït-Ali, A. (2020) Detection of Covid-19 from chest X-ray images using artificial intelligence: an early review. arXiv preprint (in press).

Inciardi, R. M., Adamo, M., Lupi, L., Cani, D. S., Di Pasquale, M., Tomasoni, D., Italia, L., Zaccone, G., Tedino, C., Fabbricatore, D., Curnis A., Faggiano, P., Gorga, E., Lombardi, C. M., Milesi, G., Vizzardi, E., Volpini, M., Nodari, S., Specchia, C., Maroldi, R., Bezzi, M. and Metra, M. (2020a) Characteristics and outcomes of patients hospitalized for COVID-19 and cardiac disease in Northern Italy. European Heart Journal 41, 1821-1829.

Inciardi, R. M., Lupi, L., Zaccone, G., Italia, L., Raffo, M., Tomasoni, D., Cani, D. S., Cerini, M., Farina, D. and Gavazzi, E. (2020b) Cardiac involvement in a patient with coronavirus disease 2019 (COVID-19). JAMA Cardiology 5, 819-824.

James, G., Witten, D., Hastie, T. and Tibshirani, R. (2013) An Introduction to Statistical Learning. Springer.

Jamshidi, M., Lalbakhsh, A., Talla, J., Peroutka, Z., Hadjilooei, F., Lalbakhsh, P., Jamshidi, M., Spada, L. L., Mirmozafari, M., Dehghani, M., Sabet, A., Roshani, S., Roshani, S., Bayat-Makou, N., Mohamadzade, B., Malek, Z., Jamshidi, A., Kiani, S., Hashemi-Dezaki, H. and Mohyuddin, W. (2020) Artificial intelligence and COVID-19: deep learning approaches for diagnosis and treatment. IEEE Access $\mathbf{8}$, 109581-109595.

Jamthikar, A., Gupta, D., Cuadrado-Godia, E., Puvvula, A., Khanna, N. N., Saba, L., Viskovic, K., Mavrogeni, S., Turk, M. and Laird, J. R. (2020b) Ultrasound-based stroke/cardiovascular risk stratification using Framingham Risk Score and ASCVD Risk Score based on "Integrated Vascular Age" instead of "Chronological Age": a multi-ethnic study of Asian Indian, Caucasian, and Japanese cohorts. Cardiovascular Diagnosis and Therapy 10, 939.

Jamthikar, A. D., Gupta, D., Johri, A. M., Mantella, L. E., Saba, L., Kolluri, R., Sharma, A. M., Viswanathan, V., Nicolaides, A. and Suri, J. S 
(2020e) Low-cost office-based cardiovascular risk stratification using machine learning and focused carotid ultrasound in an Asian-Indian cohort. Journal of Medical Systems 44, 208.

Jamthikar A, Gupta D, Khanna N, Araki T, Saba L, Nicolaides A, Sharma, A. R., Omerzu, T., Suri, H., Gupta, A., Mavrogeni, S., Turk, M., Laird, J. R., Protogerou, A. R., Sfikakis, P. P., Kitas, K. G., Viswanathan, V., Pareek, G., Miner, M. and Suri J. (2020a) A special report on changing trends in preventive stroke/cardiovascular risk assessment via Bmode ultrasonography (pp. 291-318). Cognitive Informatics, Computer Modelling, and Cognitive Science. Elsevier.

Jamthikar, A., Gupta, D., Khanna, N. N., Saba, L., Araki, T., Viskovic, K., Suri, H. S., Gupta, A., Mavrogeni, S., Turk, M., Laird, J. R., Pareek, G., Miner, M., Sfikakis, P. P., Protogerou, A., Kitas, G. D., Viswanathan, V., Nicolaides, A., Bhatt, D. L. and Suri, J. S. (2019) A low-cost machine learning-based cardiovascular/stroke risk assessment system: integration of conventional factors with image phenotypes. Cardiovascular Diagnosis and Therapy 9, 420-430.

Jamthikar, A., Gupta, D., Khanna, N. N., Saba, L., Laird, J. R. and Suri, J. S. (2020d) Cardiovascular/stroke risk prevention: a new machine learning framework integrating carotid ultrasound image-based phenotypes and its harmonics with conventional risk factors. Indian Heart Journal 72, 258-264.

Jamthikar, A., Gupta, D., Saba, L., Khanna, N. N., Araki, T., Viskovic, K., Mavrogeni, S., Laird, J. R., Pareek, G., Miner, M., Sfikakis, P. P., Protogerou, A., Viswanathan, V., Sharma, A., Nicolaides, A., Kitas, G. D. and Suri, J. S. (2020c) Cardiovascular/stroke risk predictive calculators: a comparison between statistical and machine learning models. Cardiovascular Diagnosis and Therapy 10, 919-938.

Jamthikar, A. D., Gupta, D., Saba, L., Khanna, N. N., Viskovic, K., Mavrogeni, S., Laird, J. R., Sattar, N., Johri, A. M., Pareek, G., Miner, M., Sfikakis, P. P., Protogerou, A., Viswanathan, V., Sharma, A., Kitas, G. D., Nicolaides, A., Kolluri, R. and Suri, J. S. (2020a) Artificial intelligence framework for predictive cardiovascular and stroke risk assessment models: a narrative review of integrated approaches using carotid ultrasound. Computers in Biology and Medicine 126, 104043.

Jamthikar, A. D., Gupta, D., Mantella, L. E., Saba, L., Laird, J. R., Johri, A. M. and Suri, J. S. (2020f) Multiclass machine learning vs. conventional calculators for stroke/CVD risk assessment using carotid plaque predictors with coronary angiography scores as gold standard: a 500 participants study. The International Journal of Cardiovascular Imaging (in press).

Jamthikar, A. D., Gupta, D., Puvvula, A., Johri, A. M., Khanna, N. N., Saba, L., Mavrogeni, S., Laird, J. R., Pareek, G., Miner, M., Sfikakis, P. P., Protogerou, A., Kitas, G. D., Kolluri, R., Sharma, A. M., Viswanathan, V., Rathore, V. S. and Suri, J. S. (2020g) Cardiovascular risk assessment in patients with rheumatoid arthritis using carotid ultrasound B-mode imaging. Rheumatology International 40, 1921-1939.

Jeffrey, S. (2020) Why the US has the world's highest number of Covid-19 deaths. CNN EditionOpinions. (April 13, 2020).

Jiang, F., Jiang, Y., Zhi, H., Dong, Y., Li, H., Ma, S., Wang, Y., Dong, Q., Shen, H. and Wang, Y. (2017) Artificial intelligence in healthcare: past, present and future. Stroke and Vascular Neurology 2, 230-243.

Jiang, J., Hu, Y., Tyagi, N., Zhang, P., Rimner, A., Mageras, G., Deasy, J. and Veeraraghavan, H. (2018) Tumor-aware, adversarial domain adaptation from CT to MRI for lung cancer segmentation. In, Jiang, J., Hu, Y., Tyagi, N., Zhang, P., Rimner, A., Mageras, G., Deasy, J. and Veeraraghavan, H. (eds.) Tumor-aware, adversarial domain adaptation from ct to mri for lung cancer segmentation. Medical Image Computing and Computer Assisted Intervention-MICCAI 2018 (pp. 777-785). Springer.

Jiang, S. and Shi, Z. (2020) The first disease X is caused by a highly transmissible acute respiratory syndrome coronavirus. Virologica Sinica $\mathbf{3 5}$, 263-265.

Jiang, X., Coffee, M., Bari, A., Wang, J., Jiang, X., Huang, J., Shi, J., Dai, J., Cai, J. and Zhang, T. (2020) Towards an artificial intelligence framework for data-driven prediction of coronavirus clinical severity. Computers, Materials \& Continua 63, 537-551.

Johri, A. M., Chitty, D. W., Matangi, M., Malik, P., Mousavi, P., Day, A., Gravett, M. and Simpson, C. (2013) Can carotid bulb plaque assess- ment rule out significant coronary artery disease? A comparison of plaque quantification by two- and three-dimensional ultrasound. Journal of the American Society of Echocardiography 26, 86-95.

Kagiyama, N., Shrestha, S., Farjo, P. D. and Sengupta, P. P. (2019) Artificial intelligence: practical primer for clinical research in cardiovascular disease. Journal of the American Heart Association 8, e012788.

Kamnitsas, K., Ledig, C., Newcombe, V. F. J., Simpson, J. P., Kane, A. D., Menon, D. K., Rueckert, D. and Glocker, B. (2017) Efficient multiscale 3D CNN with fully connected CRF for accurate brain lesion segmentation. Medical Image Analysis 36, 61-78.

Kelishadi, R., Sadry, G., Zadegan, N. S., Hashemipour, M., Sabet, B., Bashardoust, N., Ansari, R. and Alikhassy, H. (2004) Smoking, adolescents and health: Isfahan healthy heart programme-heart health promotion from childhood. Asia-Pacific Journal of Public Health 16, 15 22.

Keller, M., Heller, T., Lang, T., Patzelt, J., Schreieck, J., Schlensak, C., Rosenberger, P. and Magunia, H. (2020) Acute changes of global and longitudinal right ventricular function: an exploratory analysis in patients undergoing open-chest mitral valve surgery, percutaneous mitral valve repair and off-pump coronary artery bypass grafting. Cardiovascular Ultrasound 18, 32.

Khanna, N. N., Jamthikar, A. D., Araki, T., Gupta, D., Piga, M., Saba, L., Carcassi, C., Nicolaides, A., Laird, J. R., Suri, H. S., Gupta, A. Mavrogeni, S., Kitas, G. D. and Suri, J. S. (2019c) Nonlinear model for the carotid artery disease 10 -year risk prediction by fusing conventional cardiovascular factors to carotid ultrasound image phenotypes: a Japanese diabetes cohort study. Echocardiography 36, 345-361.

Khanna, N. N., Jamthikar, A. D., Gupta, D., Araki, T., Piga, M., Saba, L., Carcassi, C., Nicolaides, A., Laird, J. R., Suri, H. S., Gupta, A. Mavrogeni, S., Protogerou, A., Sfikakis, P., Kitas, G. D. and Suri, J. S. (2019d) Effect of carotid image-based phenotypes on cardiovascular risk calculator: AECRS1.0. Medical \& Biological Engineering \& Computing 57, 1553-1566.

Khanna, N. N., Jamthikar, A. D., Gupta, D., Nicolaides, A., Araki, T., Saba, L., Cuadrado-Godia, E., Sharma, A., Omerzu, T., Suri, H. S., Gupta, A., Mavrogeni, S., Turk, M., Laird, J. R., Protogerou, A., Sfikakis, P. P., Kitas, G. D., Viswanathan, V. and Suri, J. S. (2019b) Performance evaluation of 10-year ultrasound image-based stroke/cardiovascular (CV) risk calculator by comparing against ten conventional $\mathrm{CV}$ risk calculators: A diabetic study. Computers in Biology and Medicine 105, 125-143.

Khanna, N. N., Jamthikar, A. D., Gupta, D., Piga, M., Saba, L., Carcassi, C., Giannopoulos, A. A., Nicolaides, A., Laird, J. R., Suri, H. S., Mavrogeni, S., Protogerou, A. D., Sfikakis, P., Kitas, G. D. and Suri, J. S. (2019a) Rheumatoid arthritis: atherosclerosis imaging and cardiovascular risk assessment using machine and deep learning-based tissue characterization. Current Atherosclerosis Reports 21, 7.

Hense, S., Kodali, P., Kopparty, S., Kalapala, G. and Haloi, B. (2020) How Indians responded to the Arogya Setu app? Indian Journal of Public Health 64, 228 .

Kothari, V., Stevens, R. J., Adler, A. I., Stratton, I. M., Manley, S. E., Neil, H. A. and Holman, R. R. (2002) UKPDS 60: risk of stroke in type 2 diabetes estimated by the UK Prospective Diabetes Study risk engine. Stroke 33, 1776-1781.

Kotsis, V., Jamthikar, A. D., Araki, T., Gupta, D., Laird, J. R., Giannopoulos, A. A., Saba, L., Suri, H. S., Mavrogeni, S., Kitas, G. D., Viskovic, K., Khanna, N. N., Gupta, A., Nicolaides, A. and Suri, J. S. (2018) Echolucency-based phenotype in carotid atherosclerosis disease for risk stratification of diabetes patients. Diabetes Research and Clinical Practice 143, 322-331.

Krittanawong, C., Rogers, A. J., Aydar, M., Choi, E., Johnson, K. W., Wang, Z. and Narayan, S. M. (2020) Integrating blockchain technology with artificial intelligence for cardiovascular medicine. Nature Reviews Cardiology 17, 1-3.

Krizhevsky, A., Sutskever, I. and Hinton, G. E. (2012) ImageNet classification with deep convolutional neural networks. Communications of the ACM 60, 84-90.

Krishna Kumar, P., Araki, T., Rajan, J., Saba, L., Lavra, F., Ikeda, N., Sharma, A. M., Shafique, S., Nicolaides, A., Laird, J. R., Gupta, A 
and Suri, J. S. (2017) Accurate lumen diameter measurement in curved vessels in carotid ultrasound: an iterative scale-space and spatial transformation approach. Medical \& Biological Engineering \& Computing 55, 1415-1434.

Kuppili, V., Biswas, M., Sreekumar, A., Suri, H. S., Saba, L., Edla, D. R., Marinhoe, R. T., Sanches, J. M. and Suri, J. S. (2017) Extreme learning machine framework for risk stratification of fatty liver disease using ultrasound tissue characterization. Journal of Medical Systems 41, 152.

Kwenandar, F., Japar, K. V., Damay, V., Hariyanto, T. I., Tanaka, M., Lugito, N. P. H. and Kurniawan, A. (2020) Coronavirus disease 2019 and cardiovascular system: a narrative review. IJC Heart \& Vasculature 29, 100557.

LeCun, Y., Bengio, Y. and Hinton, G. (2015) Deep learning. Nature 521, 436-444.

Li, C., Yang, Y. and Ren, L. (2020a) Genetic evolution analysis of 2019 novel coronavirus and coronavirus from other species. Infection, Genetics and Evolution 82, 104285.

Li, J., Xu, Q., Cuomo, R., Purushothaman, V. and Mackey, T. (2020b) Data mining and content analysis of the Chinese social media platform Weibo during the early COVID-19 outbreak: retrospective observational infoveillance study. JMIR Public Health and Surveillance 6, e18700.

Li, X., Yu, J., Zhang, Z., Ren, J., Peluffo, A. E., Zhang, W., Zhao, Y., Yan, K., Cohen, D. and Wang, W. (2020c) Network bioinformatics analysis provides insight into drug repurposing for COVID-2019. Preprints (in press).

Libbrecht, M. W. and Noble, W. S. (2015) Machine learning applications in genetics and genomics. Nature Reviews Genetics 16, 321-332.

Libby, P. (2020) The heart in COVID-19. JACC: Basic to Translational Science 5, 537-542.

Lin, A. H., Shutt, B. J., Dendall, R. T. and Bennett, W. (2012) Multivessel spontaneous coronary artery dissection treated with staged percutanous coronary intervention in a non-postpartum female. BMJ Case Reports 2012, bcr2012007274.

Lippi, G., Henry, B. M. and Sanchis-Gomar, F. (2020) Physical inactivity and cardiovascular disease at the time of coronavirus disease 2019 (COVID-19). European Journal of Preventive Cardiology 27, 906908.

Liu, K. and Suri, J. S., inventor. Automatic vessel indentification for angiographic screening. USA: United States patent US WO/2003/008989. 30.01.2003

Lovren, F., Pan, Y., Quan, A., Teoh, H., Wang, G., Shukla, P. C., Levitt, K. S., Oudit, G. Y., Al-Omran, M., Stewart, D. J., Slutsky, A. S., Peterson, M. D., Backx, P. H., Penninger, J. M. and Verma, S. (2008) Angiotensin converting enzyme-2 confers endothelial protection and attenuates atherosclerosis. American Journal of Physiology-Heart and Circulatory Physiology 295, H1377-H1384.

Lucatelli, P., Raz, E., Saba, L., Argiolas, G. M., Montisci, R., Wintermark, M., King, K. S., Molinari, F., Ikeda, N., Siotto, P. and Suri, J. S. (2016) Relationship between leukoaraiosis, carotid intima-media thickness and intima-media thickness variability: preliminary results. European Radiology 26, 4423-4431.

Lugagne, J., Lin, H. and Dunlop, M. J. (2020) DeLTA: Automated cell segmentation, tracking, and lineage reconstruction using deep learning. PLOS Computational Biology 16, e1007673.

Mahroum, N., Adawi, M., Sharif, K., Waknin, R., Mahagna, H., Bisharat, B., Mahamid, M., Abu-Much, A., Amital, H., Luigi Bragazzi, N. and Watad, A. (2018) Public reaction to Chikungunya outbreaks in ItalyInsights from an extensive novel data streams-based structural equation modeling analysis. PLoS One 13, e0197337.

Maier, B. F. and Brockmann, D. (2020) Effective containment explains subexponential growth in recent confirmed COVID-19 cases in China. Science 368, 742-746.

Mann, D. M., Chen, J., Chunara, R., Testa, P. A. and Nov, O. (2020) COVID-19 transforms health care through telemedicine: evidence from the field. Journal of the American Medical Informatics Association 27, 1132-1135.

Martis, R. J., Acharya, U. R., Prasad, H., Chua, C. K., Lim, C. M. and Suri, J. S. (2013) Application of higher order statistics for atrial arrhythmia classification. Biomedical Signal Processing and Control 8, 888-900.

D'Agostino, R. B., Sr., Vasan, R. S., Pencina, M. J., Wolf, P. A., Cobain, M., Massaro, J. M. and Kannel, W. B. (2008) General cardiovascular risk profile for use in primary care: the Framingham Heart Study. Circulation 117, 743-753.

McClure, P., Elnakib, A., Abou El-Ghar, M., Khalifa, F., Soliman, A., El-Diasty, T., Suri, J. S., Elmaghraby, A. and El-Baz, A. (2014) Invitro and in-vivo diagnostic techniques for prostate cancer: a review. Journal of Biomedical Nanotechnology 10, 2747-2777.

Newsroom. (2020) Medicare telemedicine health care provider fact sheet. Centers for Medicare \& Medicaid Services.

Mikolajczyk, A. and Grochowski, M. (2018) 'Data augmentation for improving deep learning in image classification problem', 2018 International Interdisciplinary Phd Workshop (Iiphdw). Świnoujście, Poland.

Molinari, F., Meiburger, K. M., Saba, L., Acharya, U. R., Famiglietti, L., Georgiou, N., Nicolaides, A., Mamidi, R. S., Kuper, H. and Suri, J. S. (2014) Automated carotid IMT measurement and its validation in low contrast ultrasound database of 885 patient Indian population epidemiological study: results of AtheroEdge ${ }^{\mathrm{TM}}$ Software. Multi-Modality Atherosclerosis Imaging and Diagnosis 27, 209-219.

Molinari, F., Pattichis, C. S., Guang Z., Saba, L., Acharya, U. R., Sanfilippo, R., Nicolaides, A. and Suri, J. S. (2011) Completely automated multiresolution edge snapper-a new technique for an accurate carotid ultrasound IMT measurement: clinical validation and benchmarking on a multi-institutional database. IEEE Transactions on Image Processing 21, 1211-1222.

Molinari, F., Zeng, G. and Suri, J. S. (2010) Intima-media thickness: setting a standard for a completely automated method of ultrasound measurement. IEEE Transactions on Ultrasonics, Ferroelectrics, and Frequency Control 57, 1112-1124.

Narayanan, R., Kurhanewicz, J., Shinohara, K., Crawford, E. D., Simoneau, A. and Suri, J. S. (2009) 'MRI-ultrasound registration for targeted prostate biopsy', In 2009 IEEE International Symposium on Biomedical Imaging: From Nano to Macro. Boston, USA. IEEE.

Naudé, W. (2020) Artificial Intelligence against COVID-19: an early review. IZA Institute of Labor Economics IZA DP No. 13110.

Nicol, M., Cacoub, L., Baudet, M., Nahmani, Y., Cacoub, P., Cohen-Solal, A., Henry, P., Adle-Biassette, H. and Logeart, D. (2020) Delayed acute myocarditis and COVID-19-related multisystem inflammatory syndrome. ESC Heart Failure 27, ehf2.13047.

Ohannessian, R., Duong, T. A. and Odone, A. (2020) Global telemedicine implementation and integration within health systems to fight the COVID-19 pandemic: a call to action. JMIR Public Health and Surveillance 6, e18810.

WHO. (2020) Coronavirus disease (COVID-2019) situation reports. Emergencies-Diseases section of Coronavirus disease 2019:Situation reports.

Osondu, C. U., Vo, B., Oni, E. T., Blaha, M. J., Veledar, E., Feldman, T., Agatston, A. S., Nasir, K. and Aneni, E. C. (2018) The relationship of erectile dysfunction and subclinical cardiovascular disease: a systematic review and meta-analysis. Vascular Medicine 23, 9-20.

Oudit, G. Y., Kassiri, Z., Jiang, C., Liu, P. P., Poutanen, S. M., Penninger, J. M. and Butany, J. (2009) SARS-coronavirus modulation of myocardial ACE2 expression and inflammation in patients with SARS. European Journal of Clinical Investigation 39, 618-625.

Ozsahin, I., Sekeroglu, B., Musa, M. S., Mustapha, M. T. and Uzun Ozsahin, D. (2020) Review on diagnosis of COVID-19 from chest CT images using artificial intelligence. Computational and Mathematical Methods in Medicine 2020, 9756518.

Pacis, D. M. M., Subido, E. D. C. and Bugtai, N. T. (2018) Trends in telemedicine utilizing artificial intelligence. AIP Conference Proceedings 1933, 040009.

Pareek, G., Acharya, U. R., Sree, S. V., Swapna, G., Yantri, R., Martis, R. J., Saba, L., Krishnamurthi, G., Mallarini, G., El-Baz, A., Al Ekish, S., Beland, M. and Suri, J. S. (2013) Prostate tissue characterization/classification in 144 patient population using wavelet and higher order spectra features from transrectal ultrasound images. Technology in Cancer Research and Treatment 12, 545-557.

Peng, J., Xue, H., Wei, Z., Tuncali, I., Hao, J. and Shang, X. (2020) Inte- 
grating multi-network topology for gene function prediction using deep neural networks. Briefings in Bioinformatics bbaa036.

Pereira, S., Pinto, A., Alves, V. and Silva, C. A. (2016) Brain tumor segmentation using convolutional neural networks in MRI images. IEEE Transactions on Medical Imaging 35, 1240-1251.

Phan, T. (2020) Genetic diversity and evolution of SARS-CoV-2. Infection, Genetics and Evolution 81, 104260.

Portnoy, J., Waller, M. and Elliott, T. (2020) Telemedicine in the era of COVID-19. The Journal of Allergy and Clinical Immunology: in Practice 8, 1489-1491.

Prastawa, M., Bullitt, E., Ho, S. and Gerig, G. (2004) A brain tumor segmentation framework based on outlier detection. Medical Image Analysis 8, 275-283.

Puvvula, A., Jamthikar, A. D., Gupta, D., Khanna, N. N., Porcu, M., Saba, L., Viskovic, K., Ajuluchukwu, J. N. A., Gupta, A., Mavrogeni, S., Turk, M., Laird, J. R., Pareek, G., Miner, M., Sfikakis, P. P., Protogerou, A., Kitas, G. D., Nicolaides, A., Viswanathan, V. and Suri, J. S. (2020) Morphological carotid plaque area is associated with glomerular filtration rate: a study of south asian indian patients with diabetes and chronic kidney disease. Angiology 71, 520-535.

Ridker, P. M., Paynter, N. P., Rifai, N., Gaziano, J. M. and Cook, N. R. (2008) C-reactive protein and parental history improve global cardiovascular risk prediction. Circulation 118, 2243-2251.

Ridker, P. M., Buring, J. E., Rifai, N. and Cook, N. R. (2007) Development and validation of improved algorithms for the assessment of global cardiovascular risk in women. Journal of the American Medical Association 297, 611.

Rosvall, M., Persson, M., Östling, G., Nilsson, P. M., Melander, O., Hedblad, B. and Engström, G. (2015) Risk factors for the progression of carotid intima-media thickness over a 16-year follow-up period: the Malmö Diet and Cancer Study. Atherosclerosis 239, 615-621.

Ruan, Q., Yang, K., Wang, W., Jiang, L. and Song, J. (2020) Clinical predictors of mortality due to COVID-19 based on an analysis of data of 150 patients from Wuhan, China. Intensive Care Medicine 46, 846-848.

Saba, L., Banchhor, S. K., Araki, T., Suri, H. S., Londhe, N. D., Laird, J. R., Viskovic, K. and Suri, J. S. (2018a) Intra- and inter-operator reproducibility analysis of automated cloud-based carotid intima media thickness ultrasound measurement. Journal of Clinical and Diagnostic Research 70, 649-664.

Saba, L., Banchhor, S. K., Araki, T., Viskovic, K., Londhe, N. D., Laird, J. R., Suri, H. S. and Suri, J. S. (2018b) Intra- and inter-operator reproducibility of automated cloud-based carotid lumen diameter ultrasound measurement. Indian Heart Journal 70, 649-664.

Saba, L., Banchhor, S. K., Suri, H. S., Londhe, N. D., Araki, T., Ikeda, N., Viskovic, K., Shafique, S., Laird, J. R., Gupta, A., Nicolaides, A. and Suri, J. S. (2016) Accurate cloud-based smart IMT measurement, its validation and stroke risk stratification in carotid ultrasound: a webbased point-of-care tool for multicenter clinical trial. Computers in Biology and Medicine 75, 217-234.

Saba, L., Biswas, M., Kuppili, V., Cuadrado Godia, E., Suri, H. S., Edla, D. R., Omerzu, T., Laird, J. R., Khanna, N. N., Mavrogeni, S., Protogerou, A., Sfikakis, P. P., Viswanathan, V., Kitas, G. D., Nicolaides, A., Gupta, A. and Suri, J. S. (2019) The present and future of deep learning in radiology. European Journal of Radiology 114, 14-24.

Saba, L., Biswas, M., Suri, H. S., Viskovic, K., Laird, J. R., CuadradoGodia, E., Nicolaides, A., Khanna, N. N., Viswanathan, V. and Suri, J. S. (2019b) Ultrasound-based carotid stenosis measurement and risk stratification in diabetic cohort: a deep learning paradigm. Cardiovascular Diagnosis and Therapy 9, 439-461.

Saba, L., Jain, P. K., Suri, H. S., Ikeda, N., Araki, T., Singh, B. K., Nicolaides, A., Shafique, S., Gupta, A., Laird, J. R. and Suri, J. S. (2017) Plaque tissue morphology-based stroke risk stratification using carotid ultrasound: a polling-based pca learning paradigm. Journal of Medical Systems 41, 98

Saba, L., Jamthikar, A., Gupta, D., Khanna, N. N., Viskovic, K., Suri, H. S., Gupta, A., Mavrogeni, S., Turk, M., Laird, J. R., Pareek, G., Miner, M., Sfikakis, P. P., Protogerou, A., Kitas, G. D., Viswanathan, V., Nicolaides, A., Bhatt, D. L. and Suri, J. S. (2019) Global perspective on carotid intima-media thickness and plaque: should the current mea- surement guidelines be revisited? International Angiology 38, 451465.

Saba, L., Mallarini, G., Sanfilippo, R., Zeng, G., Montisci, R. and Suri, J. (2012a) Intima Media Thickness Variability (IMTV) and its association with cerebrovascular events: a novel marker of carotid therosclerosis? Cardiovascular diagnosis and therapy 2, 10-18.

Saba, L., Meiburger, K. M., Molinari, F., Ledda, G., Anzidei, M., Acharya, U. R., Zeng, G., Shafique, S., Nicolaides, A. and Suri, J. S. (2012b) Carotid IMT variability (IMTV) and its validation in symptomatic versus asymptomatic Italian population: can this be a useful index for studying symptomaticity? Echocardiography 29, 1111-1119.

Saba, L., Montisci, R., Molinari, F., Tallapally, N., Zeng, G., Mallarini, G. and Suri, J. S. (2012c) Comparison between manual and automated analysis for the quantification of carotid wall by using sonography. A validation study with CT. European Journal of Radiology 81, 911-918.

Saba, L. and Suri, J. S. (2013) Multi-Detector CT imaging: principles, head, neck, and vascular systems. United States: CRC Press.

Sahara, M., Ikutomi, M., Morita, T., Minami, Y., Nakajima, T., Hirata, Y., Nagai, R. and Sata, M. (2014) Deletion of angiotensin-converting enzyme 2 promotes the development of atherosclerosis and arterial neointima formation. Cardiovascular Research 101, 236-246.

Sanches, J. M., Laine, A. F. and Suri, J. S. (2012) Ultrasound imaging Springer.

Schoenhagen, P., Tuzcu, E. M. and Ellis, S. G. (2002) Plaque vulnerability, plaque rupture, and acute coronary syndromes. Circulation 106, 760762.

Shi, F., Wang, J., Shi, J., Wu, Z., Wang, Q., Tang, Z., He, K., Shi, Y. and Shen, D. (2020a) Review of artificial intelligence techniques in imaging data acquisition, segmentation and diagnosis for covid-19. IEEE Reviews in Biomedical Engineering.

Shi, S., Qin, M., Shen, B., Cai, Y., Liu, T., Yang, F., Gong, W., Liu, X., Liang, J., Zhao, Q., Huang, H., Yang, B. and Huang, C. (2020) Association of cardiac injury with mortality in hospitalized patients with COVID-19 in Wuhan, China. JAMA Cardiol 5, 802-810.

Shorten, C. and Khoshgoftaar, T. M. (2019) A survey on image data augmentation for deep learning. Journal of Big Data 6, 60 .

Siddiqi, H. K. and Mehra, M. R. (2020) COVID-19 illness in native and immunosuppressed states: a clinical-therapeutic staging proposal. The Journal of Heart and Lung Transplantation 39, 405-407.

Signorini, A., Segre, A. M. and Polgreen, P. M. (2011) The use of Twitter to track levels of disease activity and public concern in the U.S. during the influenza a H1N1 pandemic. PLoS One 6, e19467.

Siripanthong, B., Nazarian, S., Muser, D., Deo, R., Santangeli, P., Khanji, M. Y., Cooper Jr, L. T. and Chahal, C. A. A. (2020) Recognizing COVID-19-related myocarditis: the possible pathophysiology and proposed guideline for diagnosis and management. Heart Rhythm 17, 1463-1471.

Skandha, S. S., Gupta, S. K., Saba, L., Koppula, V. K., Johri, A. M., Khanna, N. N., Mavrogeni, S., Laird, J. R., Pareek, G., Miner, M., Sfikakis, P. P., Protogerou, A., Misra, D. P., Agarwal, V., Sharma, A. M., Viswanathan, V., Rathore, V. S., Turk, M., Kolluri, R., Viskovic, K., Cuadrado-Godia, E., Kitas, G. D., Nicolaides, A. and Suri, J. S. (2020) 3-D optimized classification and characterization artificial intelligence paradigm for cardiovascular/stroke risk stratification using carotid ultrasound-based delineated plaque: Atheromatic ${ }^{\mathrm{TM}}$ 2.0. Computers in Biology and Medicine 125, 103958.

Skourt, B. A., El Hassani, A. and Majda, A. (2018) Lung CT image segmentation using deep neural networks. Procedia Computer Science 127, 109-113.

Smith, A. C., Thomas, E., Snoswell, C. L., Haydon, H., Mehrotra, A., Clemensen, J. and Caffery, L. J. (2020) Telehealth for global emergencies: implications for coronavirus disease 2019 (COVID-19). Journal of Telemedicine and Telecare 26, 309-313.

Song, P. X., Wang, L., Zhou, Y., He, J., Zhu, B., Wang, F., Tang, L. and Eisenberg, M. (2020) An epidemiological forecast model and software assessing interventions on COVID-19 epidemic in China. Journal of Data Science 18, P409-432.

South, A. M., Diz, D. I. and Chappell, M. C. (2020) COVID-19, ACE2, and the cardiovascular consequences. American Journal of Physiology- 
Heart and Circulatory Physiology 318, H1084-H1090.

Stebbing, J., Phelan, A., Griffin, I., Tucker, C., Oechsle, O., Smith, D. and Richardson, P. (2020) COVID-19: combining antiviral and antiinflammatory treatments. The Lancet Infectious Diseases 20, 400-402.

Stevens, R. J., Kothari, V., Adler, A. I. and Stratton, I. M. (2001) The UKPDS risk engine: a model for the risk of coronary heart disease in Type II diabetes (UKPDS 56). Clinical Science 101, 671-679.

Sugiyama, S., Okada, Y., Sukhova, G. K., Virmani, R., Heinecke, J. W. and Libby, P. (2001) Macrophage myeloperoxidase regulation by granulocyte macrophage colony-stimulating factor in human atherosclerosis and implications in acute coronary syndromes. The American Journal of Pathology 158, 879-891.

Suri, J., Turk, M., Jamthikar, A., Gupta, D., Khanna, N., Araki, T., Saba, L., Cuadrado-Godia, E., Sharma, A. and Omerzu, T. 2019. Performance evaluation of AECRS1. 0 using stroke risk calculators. In European Journal of Neurology. Vol. 26. Wiley 111 River ST, Hoboken 07030-5774, NJ USA. 280-281.

Suri, J. S. (2000) Computer vision, pattern recognition and image processing in left ventricle segmentation: the last 50 years. Pattern Analysis \& Applications 3, 209-242.

Suri, J. S., Kathuria, C. and Molinari, F. (2010) Atherosclerosis disease management. Springer Science \& Business Media.

Suri, J. S., Liu, K., Singh, S., Laxminarayan, S. N., Zeng, X. and Reden, L. (2002) Shape recovery algorithms using level sets in 2-D/3-D medical imagery: a state-of-the-art review. IEEE Transactions on Information Technology in Biomedicine 6, 8-28.

Suri, J. S., Puvvula, A., Biswas, M., Majhail, M., Saba, L., Faa, G., Singh, I. M., Oberleitner, R., Turk, M., Chadha, P. S., Johri, A. M., Sanches, J. M., Khanna, N. N., Viskovic, K., Mavrogeni, S., Laird, J. R., Pareek, G., Miner, M., Sobel, D. W., Balestrieri, A., Sfikakis, P. P., Tsoulfas, G., Protogerou, A., Misra, D. P., Agarwal, V., Kitas, G. D., Ahluwalia, P., Kolluri, R., Teji, J., Maini, M. A., Agbakoba, A., Dhanjil, S. K., Sockalingam, M., Saxena, A., Nicolaides, A., Sharma, A., Rathore, V., Ajuluchukwu, J. N. A., Fatemi, M., Alizad, A., Viswanathan, V., Krishnan, P. R. and Naidu, S. (2020) COVID-19 pathways for brain and heart injury in comorbidity patients: a role of medical imaging and artificial intelligence-based COVID severity classification: a review. Computers in Biology and Medicine 124, 103960.

Suri, J. S., Wilson, D. and Laxminarayan, S. (2005) Handbook of biomedical image analysis. Springer Science \& Business Media.

Tan, T., Li, Z., Liu, H., Zanjani, F. G., Ouyang, Q., Tang, Y., Hu, Z. and Li, Q. (2018) Optimize transfer learning for lung diseases in bronchoscopy using a new concept: sequential fine-tuning. IEEE Journal of Translational Engineering in Health and Medicine 6, 1-8.

Tan, W. and Aboulhosn, J. (2020) The cardiovascular burden of coronavirus disease 2019 (COVID-19) with a focus on congenital heart disease. International Journal of Cardiology 309, 70-77.

Tandel, G. S., Balestrieri, A., Jujaray, T., Khanna, N. N., Saba, L. and Suri, J. S. (2020) Multiclass magnetic resonance imaging brain tumor classification using artificial intelligence paradigm. Computers in Biology and Medicine 122, 103804

Tandel, G. S., Biswas, M., Kakde, O. G., Tiwari, A., Suri, H. S., Turk, M., Laird, J., Asare, C., Ankrah, A. A., Khanna, N. N., Madhusudhan, B. K., Saba, L. and Suri, J. S. (2019) A review on a deep learning perspective in brain cancer classification. Cancers 11, 111.

Tavazzi, G., Pellegrini, C., Maurelli, M., Belliato, M., Sciutti, F., Bottazzi, A., Sepe, P. A., Resasco, T., Camporotondo, R., Bruno, R., Baldanti, F., Paolucci, S., Pelenghi, S., Iotti, G. A., Mojoli, F. and Arbustini, E. (2020) Myocardial localization of coronavirus in COVID-19 cardiogenic shock. European Journal of Heart Failure 22, 911-915.

Thamman, R., Gulati, M., Narang, A., Utengen, A., Mamas, M. A. and Bhatt, D. L. (2020) Twitter-based learning for continuing medical education? European Heart Journal (in press).

Thomas, E., Gallagher, R. and Grace, S. L. (2020) Future-proofing cardiac rehabilitation: transitioning services to telehealth during COVID-19. European Journal of Preventive Cardiology (in press).

Tikoo, K., Patel, G., Kumar, S., Karpe, P. A., Sanghavi, M., Malek, V. and Srinivasan, K. (2015) Tissue specific up regulation of ACE2 in rabbit model of atherosclerosis by atorvastatin: role of epigenetic his- tone modifications. Biochemical Pharmacology 93, 343-351.

Turner, A. J., Hiscox, J. A. and Hooper, N. M. (2004) ACE2: from vasopeptidase to SARS virus receptor. Trends in Pharmacological Sciences 25, 291-294.

Vaishya, R., Javaid, M., Khan, I. and Haleem, A. (2020) Artificial intelligence (AI) applications for COVID-19 pandemic. Diabetes \& metabolic syndrome. Diabetes \& Metabolic Syndrome 14, 337-339.

van Valen, D. A., Kudo, T., Lane, K. M., Macklin, D. N., Quach, N. T., DeFelice, M. M., Maayan, I., Tanouchi, Y., Ashley, E. A. and Covert, M. W. (2016) Deep learning automates the quantitative analysis of individual cells in live-cell imaging experiments. PLoS Computational Biology 12, e1005177.

Vidal-Alaball, J., Acosta-Roja, R., Pastor Hernández, N., Sanchez Luque, U., Morrison, D., Narejos Pérez, S., Perez-Llano, J., Salvador Vèrges, A. and López Seguí, F. (2020) Telemedicine in the face of the COVID19 pandemic. AtenciÓN Primaria 52, 418-422.

Viswanathan, V., Jamthikar, A. D., Gupta, D., Puvvula, A., Khanna, N. N., Saba, L., Viskovic, K., Mavrogeni, S., Laird, J. R. and Pareek, G. (2020a) Does the carotid bulb offer a better 10-Year CVD/Stroke risk assessment compared to the common carotid artery? A 1516 ultrasound scan study. Angiology 71, 920-933.

Viswanathan, V., Jamthikar, A. D., Gupta, D., Puvvula, A., Khanna, N. N., Saba, L., Viskovic, K., Mavrogeni, S., Turk, M. and Laird, J. R. (2020b) Integration of eGFR biomarker in image-based CV/Stroke risk calculator: a south Asian-Indian diabetes cohort with moderate chronic kidney disease. International Angiology 39, 290-306.

Viswanathan, V., Jamthikar, A. D., Gupta, D., Puvvula, A., Khanna, N. N., Saba, L., Viskovic, K., Mavrogeni, S., Turk, M., Laird, J. R., Pareek, G., Miner, M., Ajuluchukwu, J., Sfikakis, P. P., Protogerou, A., Kitas, G. D., Nicolaides, A., Sharma, A. and Suri, J. S. (2020c) Integration of estimated glomerular filtration rate biomarker in image-based cardiovascular disease/stroke risk calculator: a south Asian-Indian diabetes cohort with moderate chronic kidney disease. International Angiology 39, 290-306.

Viswanathan, V., Jamthikar, A. D., Gupta, D., Shanu, N., Puvvula, A., Khanna, N. N., Saba, L., Omerzum, T., Viskovic, K. and Mavrogeni, S. (2020d) Low-cost preventive screening using carotid ultrasound in patients with diabetes. Frontiers in Bioscience 25, 1132-1171.

Wan, Y., Shang, J., Graham, R., Baric, R. S. and Li, F. (2020) Receptor recognition by the novel coronavirus from wuhan: an analysis based on decade-long structural studies of SARS coronavirus. 94, e0012700120 .

Wang, C. and Smedby, Ö. (2018) Automatic whole heart segmentation using deep learning and shape context. Lecture Notes in Computer Science 353, 242-249.

Wang, D., Hu, B., Hu, C., Zhu, F., Liu, X., Zhang, J., Wang, B., Xiang, H., Cheng, Z. and Xiong, Y. (2020) Clinical characteristics of 138 hospitalized patients with 2019 novel coronavirus-infected pneumonia in Wuhan, China. JAMA 323, 1061-1069.

Wang, L., Zhou, X., Yin, Y., Mai, Y., Wang, D. and Zhang, X. (2019) Hyperglycemia induces neutrophil extracellular traps formation through an NADPH oxidase-dependent pathway in diabetic retinopathy. Frontiers in Immunology 9, 3067.

Wang, X. and Bhatt, D. L. (2020) COVID-19: an unintended force for medical revolution. Journal of Invasive Cardiology 32, E81-E82.

Williams, V. R. and Scholey, J. W. (2018) Angiotensin-converting enzyme 2 and renal disease. Current Opinion in Nephrology and Hypertension 27, 35-41.

Wong, Z. S. Y., Zhou, J. and Zhang, Q. (2019) Artificial intelligence for infectious disease big data analytics. Infection, Disease \& Health 24, 44-48.

Worldometer. (2020) COVID-19 coronavirus pandemic. Coronavirus sections of Worldometer.

Woudstra, L., Juffermans, L. J. M., van Rossum, A. C., Niessen, H. W. M. and Krijnen, P. A. J. (2018) Infectious myocarditis: the role of the cardiac vasculature. Heart Failure Reviews 23, 583-595.

Wu, C., Hu, X., Song, J., Du, C., Xu, J., Yang, D., Chen, D., Zhong, M., Jiang, J. and Xiong, W. (2020) Heart injury signs are associated with higher and earlier mortality in coronavirus disease 2019 (COVID-19). 
MedRxiv (in press).

Wu, K., Peng, G., Wilken, M., Geraghty, R. J. and Li, F. (2012) Mechanisms of host receptor adaptation by severe acute respiratory syndrome coronavirus. Journal of Biological Chemistry 287, 8904-8911.

Wu, Q., Zhou, L., Sun, X., Yan, Z., Hu, C., Wu, J., Xu, L., Li, X., Liu, H., Yin, P., Li, K., Zhao, J., Li, Y., Wang, X., Li, Y., Zhang, Q., Xu, G. and Chen, H. (2017) Altered lipid metabolism in recovered SARS patients twelve years after infection. Scientific Reports 7, 9110.

Wu, Z. and McGoogan, J. M. (2020) Characteristics of and important lessons from the coronavirus disease 2019 (COVID-19) outbreak in China. Journal of the American Medical Association 323, 1239.

Xiong, T., Redwood, S., Prendergast, B. and Chen, M. (2020) Coronaviruses and the cardiovascular system: acute and long-term implications. European Heart Journal 41, 1798-1800.

Xu, B., Kocyigit, D., Grimm, R., Griffin, B. P. and Cheng, F. (2020) Applications of artificial intelligence in multimodality cardiovascular imaging: a state-of-the-art review. Progress in Cardiovascular Diseases $\mathbf{6 3}$ 367-376.

Yan, L., Zhang, H.-T., Xiao, Y., Wang, M., Sun, C., Liang, J., Li, S., Zhang, M., Guo, Y. and Xiao, Y. (2020a) Prediction of criticality in patients with severe Covid-19 infection using three clinical features: a machine learning-based prognostic model with clinical data in Wuhan. MedRxiv (in press).

Yan, L., Zhang, H.-T., Xiao, Y., Wang, M., Sun, C., Liang, J., Li, S., Zhang, M., Guo, Y. and Xiao, Y. (2020b) Prediction of survival for severe Covid-19 patients with three clinical features: development of a machine learning-based prognostic model with clinical data in Wuhan. MedRxiv (in press)

Yassine, H. M. and Shah, Z. (2020) How could artificial intelligence aid in the fight against coronavirus? Expert Review of Anti-Infective Therapy 18, 493-497.

Yousif, M. H. M., Dhaunsi, G. S., Makki, B. M., Qabazard, B. A., Akhtar, S. and Benter, I. F. (2012) Characterization of Angiotensin-(1-7) effects on the cardiovascular system in an experimental model of Type- 1 diabetes. Pharmacological Research 66, 269-275.

Yuan, W., Zhao, X., Hu, F., Bai, C. and Tang, F. (2019) Evaluation of early gadolinium enhancement (EGE) and cardiac functional parameters in cine-magnetic resonance imaging (MRI) on artificial intelligence in pa- tients with acute myocarditis: a case-controlled observational study Medical Science Monitor 25, 5493-5500.

Zhang, C., Zhao, Y. X., Zhang, Y. H., Zhu, L., Deng, B. P., Zhou, Z. L., Li, S. Y., Lu, X. T., Song, L. L., Lei, X. M., Tang, W. B., Wang, N., Pan, C. M., Song, H. D., Liu, C. X., Dong, B., Zhang, Y. and Cao, Y. (2010) Angiotensin-converting enzyme 2 attenuates atherosclerotic lesions by targeting vascular cells. Proceedings of the National Academy of Sciences 107, 15886-15891.

Zhang, H. and Baker, A. (2018) Recombinant human ACE2: acing out angiotensin II in ARDS therapy. Critical Care 21, 305.

Zhang, J., Ma, K., Li, H., Liao, M. and Qi, W. (2020a) The continuous evolution and dissemination of 2019 novel human coronavirus. Journal of Infection 80, 671-693.

Zhang, L., Zhu, F., Xie, L., Wang, C., Wang, J., Chen, R., Jia, P., Guan, H. Q., Peng, L., Chen, Y., Peng, P., Zhang, P., Chu, Q., Shen, Q., Wang, Y., Xu, S. Y., Zhao, J. P. and Zhou, M. (2020b) Clinical characteristics of COVID-19-infected cancer patients: a retrospective case study in three hospitals within Wuhan, China. Annals of Oncology 31, 894-901.

Zhao, S., Lin, Q., Ran, J., Musa, S. S., Yang, G., Wang, W., Lou, Y., Gao, D., Yang, L., He, D. and Wang, M. H. (2020) The basic reproduction number of novel coronavirus (2019-nCoV) estimation based on exponential growth in the early outbreak in China from 2019 to 2020: a reply to Dhungana. International Journal of Infectious Diseases 94, 148-150.

Zhao, X. and Yuan, W. (2020) The 4D B-spline method of calculating left ventricular functional parameters of cardiac MRI to evaluate myocardial injury of the apical segment in patients with myocarditis: a case-controlled observational study. Quantitative Imaging in Medicine and Surgery 10, 2133-2143.

Zheng, Y., Ma, Y., Zhang, J. and Xie, X. (2020) COVID-19 and the cardiovascular system. Nature Reviews Cardiology 17, 259-260.

Zlochower, A., Chow, D. S., Chang, P., Khatri, D., Boockvar, J. A. and Filippi, C. G. (2020) Deep learning AI applications in the imaging of glioma. Topics in Magnetic Resonance Imaging 29, 115-100.

Zou, X., Chen, K., Zou, J., Han, P., Hao, J. and Han, Z. (2020) Singlecell RNA-seq data analysis on the receptor ACE2 expression reveals the potential risk of different human organs vulnerable to 2019-nCoV infection. Frontiers of Medicine 14, 185-192. 